\title{
GCU
}

Glasgow Caledonian

University

University for the Common Good

\section{Software simulation and experimental characterisation of a rotationally asymmetrical concentrator under direct and diffuse solar radiation}

Freier, Daria; Muhammad-Sukki, Firdaus; Abu Bakar, Siti Hawa Binti; Ramirez-Iniguez, Roberto; Mas'ud, Abdullahi Abubakar; Albarracín, Ricardo; Ardila-Rey, Jorge Alfredo; Munir, Abu ; Yasin, Siti; Bani, Nurul Aini

Published in:

Energy Conversion and Management

DOI:

10.1016/j.enconman.2016.05.072

Publication date:

2016

Document Version

Author accepted manuscript

Link to publication in ResearchOnline

Citation for published version (Harvard):

Freier, D, Muhammad-Sukki, F, Abu Bakar, SHB, Ramirez-Iniguez, R, Mas'ud, AA, Albarracín, R, Ardila-Rey, JA, Munir, A, Yasin, S \& Bani, NA 2016, 'Software simulation and experimental characterisation of a rotationally asymmetrical concentrator under direct and diffuse solar radiation', Energy Conversion and Management, vol. 122, pp. 223-238. https://doi.org/10.1016/j.enconman.2016.05.072

\section{General rights}

Copyright and moral rights for the publications made accessible in the public portal are retained by the authors and/or other copyright owners and it is a condition of accessing publications that users recognise and abide by the legal requirements associated with these rights.

Take down policy

If you believe that this document breaches copyright please view our takedown policy at https://edshare.gcu.ac.uk/id/eprint/5179 for details of how to contact us. 


\section{Software simulation and experimental characterisation of a rotationally asymmetrical concentrator under direct and diffuse solar radiation}

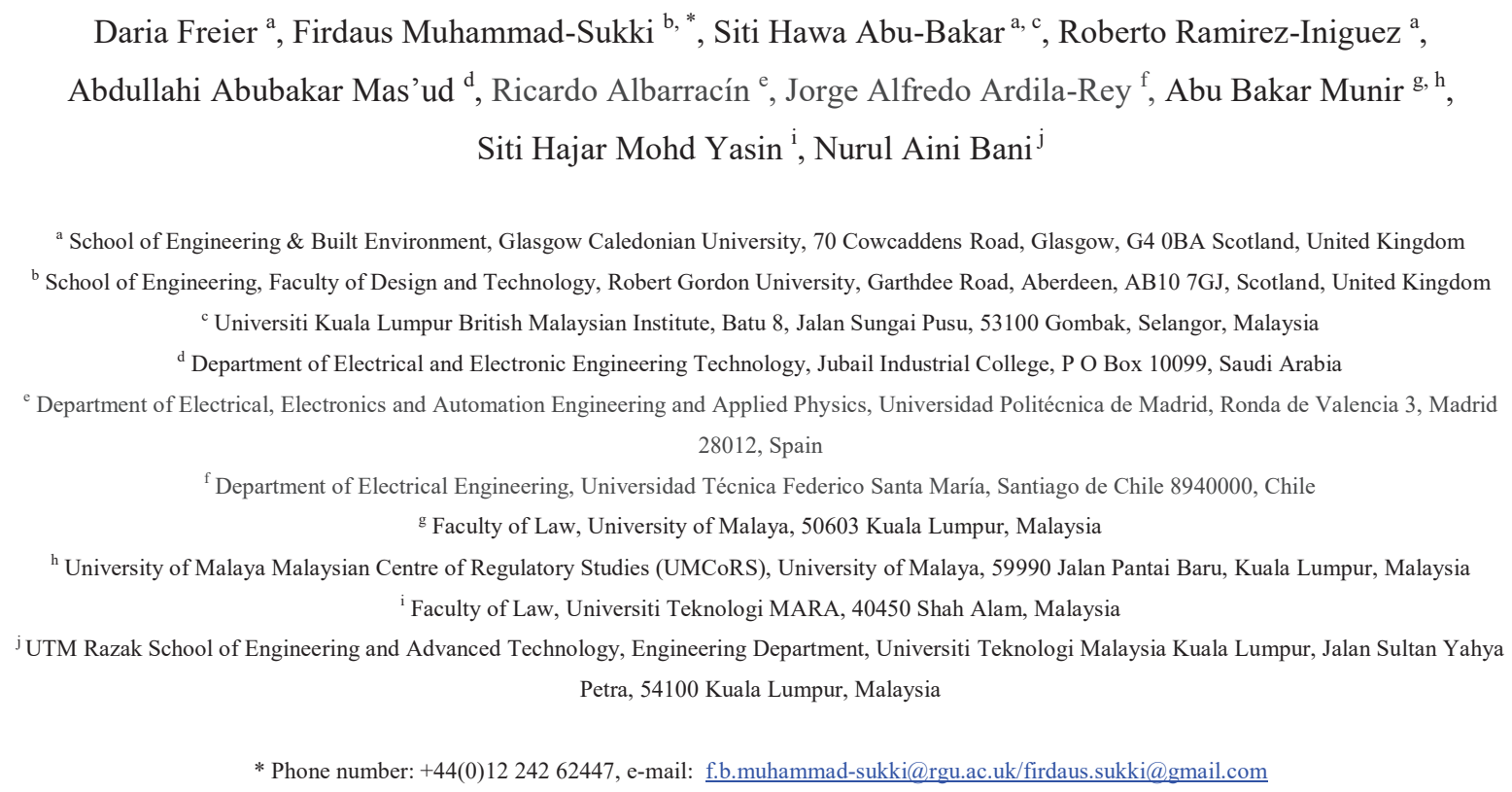

Abstract: Making housing carbon neutral is one of the European Union (EU) targets with the aim to reduce energy consumption and to increase on-site renewable energy generation in the domestic sector. Optical concentrators have a strong potential to minimise the cost of building integrated photovoltaic (BIPV) systems by replacing expensive photovoltaic (PV) material whilst maintaining the same electrical output. In this work, the performance of a recently patented optical concentrator known as the rotationally asymmetrical dielectric totally internally reflective concentrator (RADTIRC) was analysed under direct and diffuse light conditions. The RADTIRC has a geometrical concentration gain of 4.969 and two half acceptance angles of $\pm 40^{\circ}$ and $\pm 30^{\circ}$ respectively along the two axes. Simulation and experimental work has been carried out to determine the optical concentration gain and the angular response of the concentrator. It was found that the RADTIRC has an optical concentration gain of 4.66 under direct irradiance and 1.94 under diffuse irradiance. The experimental results for the single concentrator showed a reduction in concentration gain of $4.2 \%$ when compared with simulation data.

Keyword: photovoltaic; optical concentrator; asymmetrical concentrator. 


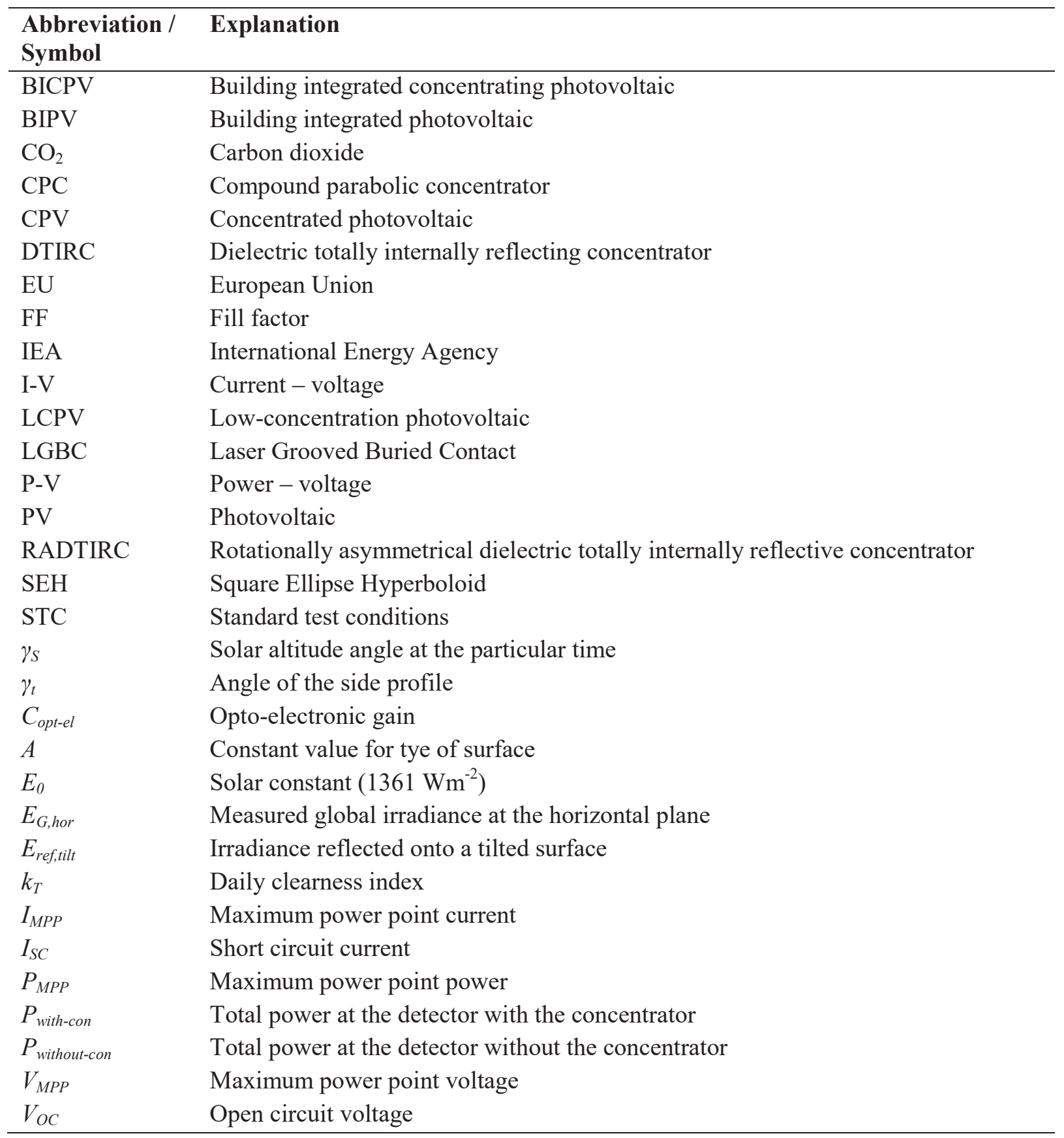

Since the 1960s, scientists have argued that global warming and the increase of carbon dioxide $\left(\mathrm{CO}_{2}\right)$ in the atmosphere are interconnected. It was also found that human emissions are extremely likely to be the reason for it [1]. More than half of a century later, after several conferences on climate change and a signed Kyoto protocol, the amount of $\mathrm{CO}_{2}$ emissions is still rising [2]. The European Union (EU) targets to cut greenhouse gas 
emissions below 1990 levels by $40 \%$ by 2030 and by $80-95 \%$ by 2050 [3]. This involves a higher share of low carbon technologies and an increase in technology efficiency, where the EU targets are $27 \%$ and $30 \%$ respectively. Furthermore a reduction in energy consumption is necessary [4].

The building sector has a lot of potential for improvement as it consumes about $40 \%$ of the world's energy and causes one third of global $\mathrm{CO}_{2}$ emissions [5]. Therefore all new buildings shall be nearly carbon neutral by 2020 [6]. This target can be achieved by implementing sustainable design strategies regarding building insulation, lightening etc. along with onsite renewable energy generation. Photovoltaic (PV), solar thermal, geothermal and heat pumps are the main technologies used in buildings. In order to meet the energy generation requirements, these technological options need to become more attractive through an increase in efficiency and thus reductions in total cost.

From 2006 until 2015 the overall cost for photovoltaic roof systems in Germany dropped by $60 \%[7,8]$. Due to supportive policies granting a fixed feed-in tariff price and thanks to the cost drop, a favourable development of solar energy generation was triggered. Hence by the first quarter 2014, solar photovoltaic made up to 70\% of Germany's gross renewable energy electricity consumption [9]. However with a new reform enacted in August 2014 [10], favourable conditions for renewables have been reduced. In order to keep the technology viable, further reductions in investment cost are necessary. The most expensive part of solar photovoltaic systems is still the PV material, which constitutes about $32.85 \%$ of the total cost [11].

The manufacturing process of crystalline silicon and thin-film solar cells has been widely optimised while efficiency improvement of these technologies has been slowing down during the last decades [12]. One possibility for further technology improvement is the multijunction cells technology which uses multiple layers of semiconductor material. Each layer has a different interval of spectral response what leads to high efficiencies. The experimental world record is held by Soitec and the Fraunhofer ISE where a cell efficiency of $46 \%$ was achieved [13]. However the manufacturing process for multijunction cells is very complicated and expensive. Combined with optical concentrators, multijunction cells are used in concentrated photovoltaic (CPV) systems [14].

CPV system is another way to increase the efficiency of the technology, by replacing expensive solar cell material with cheap optical concentrators. CPV can be applied in building integrated photovoltaic (BIPV) systems where a significant rise was reported lately [15]. BIPV systems can be a huge contributor to a carbon neutral household. Those systems 
generate electricity and function as structural elements of buildings simultaneously. According to Transparency Market Research [16], the annual installations of BIPV are expected to grow at a rate of $18.7 \%$ between 2013 and 2019, and they are expected to reach a capacity of 1152.3 MW by 2019 .

The main advantage of BIPV is the generation of electricity right at the consumer premises, with the PV modules integrated into the building. This involves many monetary and structural advantages compared to freestanding photovoltaic systems. Some of these advantages include [15]: (i) no land acquisition required; (ii) no supporting structures are necessary since the PV modules are mounted onto the building or integrated into the building; (iii) reduced cabling cost since buildings are already connected to the grid; (iv) less distribution and transportation losses since generated electricity can be consumed within the building, and (v) less building cost, as building material is replaced by PV structures.

Moreover BIPV systems can function as sun protection, noise insulation, shelter against the weather, thermal protection and have positive illumination effects. The photovoltaic system can be mounted outside in front of the cladding, it can be integrated into the cladding or it can replace façade, wall or roof structures [17-20]. Regardless of the positive appearance and design advantages, high efficiencies and a good weather tightness, the viability of BIPV sytems is still low due to its high investment cost [21]. Saving expensive solar cell material by concentrating sun light through cheap optical devices is a favourable way to reduce costs. Recently, new solar concentrator designs for BIPV have been introduced during the last decades with the aim of further reducing the installation cost of the BIPV system. These applications are categorised as building integrated concentrating photovoltaic (BICPV) systems which typically employ low-concentration PV (LCPV) designs.

Mallick et al. [22] studied the performance of an asymmetric compound parabolic concentrator (CPC) installed in University of Ulster, Northern Ireland, and found that their LCPV panel increased the maximum power generation by $1.62 \mathrm{X}$ when compared to a nonconcentrating PV panel. Zacharopoulos et al. [23] studied the performance of a dielectric symmetric CPC. If such system is installed in Crete, Greece, their simulation results showed that the LCPV system could collect 2.7 times more solar radiation than a non-concentrating PV system. Sarmah and Mallick [24] evaluated the outdoor performance of a dielectric asymmetric CPC in Edinburgh, United Kingdom and found that their LCPV design generated 2.27 times more output power than the non-concentrating design during a day with sunny intervals. Li et al. [25] compared the performance of lens-walled CPC with a classic mirror 
CPC. They demonstrated that their concentrator design produced a more uniform flux distribution and therefore improved the output of the system when compared with the mirror CPC. Baig et al. [21] analysed the performance of a dielectric cross CPC and found that their LCPV device increased the maximum power ratio up to 2.67 when compared to a nonconcentrating counterpart. Abu-Bakar et al. characterised a rotationally asymmetrical CPC and found that their LCPV device achieved an opto-electronic gain of 3.01X [26] when compared to a bare cell. Muhammad-Sukki et al. [27] studied a SolarBrane that employs extrusions of dielectric totally internally reflecting concentrators (DTIRC). They showed that for an installation in Malaysia, a SolarBrane could generate similar electrical output when compared to a conventional non-concentrating design but utilise only $30 \%$ of the amount of PV material. Sellami et al. [28] investigated the optical efficiency of a Square Elliptical $4 \mathrm{X}$ could achieved an optical efficiency of $40 \%$ for a half-acceptance angle of $\pm 60^{\circ}$.

The concentrator which was analysed numerically and experimentally in this work, was proposed by Muhammad-Sukki et al. [15,29] and the patent has been granted recently [30]. It is categorised as a hybrid type concentrator, named rotationally asymmetrical dielectric totally internally reflecting concentrator (RADTIRC). This paper aims at presenting the performance of the RADTIRC under direct and diffuse radiations, via simulations and experiments. It is the first time such detailed analyses on the performance of the RADTIRC are carried out. Section 2 describes the RADTIRC and its advantages. The simulation work is described in the following Section 3, which includes a short introduction to the software and the methods used. This is followed by Section 4, in which the experimental setup and the devices are explained. The results are discussed and compared after each simulation and experiment respectively. In the last Section, conclusions from the work carried out are drawn and planned future work is presented to the readers.

\section{Design of the concentrator}

The RADTIRC is a variation of dielectric totally internally reflecting concentrator (DTIRC) and the process to design the RADTIRC has been discussed in detail in [15]. In contrast to the rotationally symmetric version, the RADTIRC is mirror symmetrical in two axes parallel to the base of the concentrator. Hence the entrance aperture is not a semihemispherical dome shape as in the DTIRC, but a faceted one, with different fields-of-view on different planes. This is due to the design process which was undertaken to create an 
152 efficient optical shape, by generating a 2D design for each angle of rotation in MATLAB ${ }^{\circledR}$ 153 (see Figure 1).

Figure 1: Generation of an RADTIRC design from a series of 2D DTIRC design [15].

The concentrator has a half-acceptance angle along the $\mathrm{x}$-axis of $\pm 30^{\circ}$ representing the change of the solar altitude angle during the year. An example of a variation of the RADTIRC is presented in Figure 2. The rays are refracted at the curved entrance aperture and reflected at the hyperboloid side profile towards the cell (Figure 2(b)). The side profile along the z-axis is parabolic and has a half acceptance angle of $\pm 40^{\circ}$ which represents the change of the angle of incidence during the day (Figure 2(c)). As a result, this concentrator does not require an electromechanical tracking system, but can capture sunlight during the year and during the day acting as a passive tracker [15].

The total height of the manufactured prototype concentrator is $30 \mathrm{~mm}$ and therefore is

\section{Simulation performance analysis} suitable for appliance in double glazed windows. The exit aperture is designed to be square, with a size of $10 \mathrm{~mm} \times 10 \mathrm{~mm}$, as the fabrication of square (and rectangular) solar cells is easier than the fabrication of circular solar cells which are utilised in rotational symmetry designs [31]. The geometrical concentration gain - the area ratio of the entrance aperture to the exit aperture [32] is calculated to be 4.9069 [29]. The information about the geometrical concentration gain is crucial in estimating the reduction of PV material when compared to the non-concentrating PV system. For example, if the RADTIRC has a gain of 5, an RADTIRCPV module would only require one-fifth of solar PV material and could theoretically generate the same electrical output as a non-concentrating system.

Ray tracing is used to design and analyse optical imaging and illumination systems. Commercial software like ZEMAX, Code, Oslo and OptisWorks perform an analysis in vector form using ray tracing algorithms at high speed. In this project the ZEMAX OpticStudio was used to carry out the optical analysis. OpticStudio is an industrial standard optical system design software, which is developed for sequential lens design, analysis and 
optimisation, non-sequential optical system design, polarization, thin film modelling and has the function of mechanical CAD Import/Export [33].

The main aim of the simulations in this paper is to obtain the optical efficiency (the ratio of the flux at the exit aperture (in W) to the flux at the entrance aperture (in W) $[32,28]$ ) and optical concentration gain (the product of optical efficiency and the geometrical concentration gain [28]) of the RADTIRC under direct and diffuse light. The direct light is unidirectional and theoretically parallel whereas diffuse light comes from all directions. Since the performance of the concentrator depends on the angle of incident of rays, the optical concentration gain has to be defined for direct and diffuse light separately. The two different simulation setups were created in order to obtain an optical concentration gain and optical efficiency for both direct and diffuse light.

\subsection{Direct light simulation}

\subsubsection{Method}

Figure 3 shows the flow chart on how the direct light simulation is carried out. A square power source was chosen to produce a million rays at a power of $1000 \mathrm{~W}$. The size of the source is big enough to cover the concentrator both when directly opposite it and at an angle. The detector is placed at a distance of $350 \mathrm{~mm}$ in regards to the light source which is the working distance of the sun simulator during the experiments. Since the concentration ratio depends on the incident angle of light, the performance of the concentrator at different solar altitude and azimuth angles needs to be determined. Simulations were carried out at angles of incidence between $0^{\circ}$ and $60^{\circ}$ in $5^{\circ}$ steps along the $\mathrm{x}$-axis and the z-axes of the concentrator.

Figure 3: Flow chart to carry out the direct light simulation: (a) determining the flux at the entrance aperture, and (b) determining the flux at the exit aperture of the RADTIRC.

In order to obtain the optical efficiency, total ray hits at the entrance aperture and at the exit aperture need to be known. From Figure 2(a), it can be seen that the entrance aperture of the RADTIRC is a faceted dome-shape. The built-in detector in ZEMAX is incapable of creating a specific faceted dome-shape to cater for the RADTIRC (it can only cater for a 
rectangular shape such as the one attached at the exit aperture of the RADTIRC or a circular shape such as the one attached at the exit aperture of the 3D rotationally symmetrical DTIRC. Therefore, some 'modifications' were carried out to obtain the flux at the entrance aperture.

The first simulation is carried out without the 'cap' of the concentrator placed on the detector as shown in Figure 4 and the second simulation with both the detector and the 'cap'. The 'cap' is created by joining the $\mathrm{x}-\mathrm{y}$ points on the entrance aperture of the concentrator to create a perimeter. The z-coordinate of each point is removed. This is based on the fundamental of any $3 \mathrm{D}$ concentrator that only rays entering the entrance aperture of the concentrator are compressed in the $\mathrm{x}$ and $\mathrm{y}$ directions perpendicular to the optical axis and are directed to the exit aperture of the concentrator [32,34]. The 'cap' and the detector material are both set to absorb the rays. The difference in total hits on the detector between the two simulations is the flux at the entrance aperture of the concentrator. The 'cap' was created in AutoCAD using MATLAB coordinates of the concentrator design.

Figure 4: Simulation setup for obtaining the flux at the entrance aperture.

Having obtained flux at the entrance, flux at the exit needs to be determined as well. In order to do that, a detector of $100 \mathrm{~mm}^{2}$ in size according to the solar cell size was attached to the bottom of the concentrator. It detects the rays which entered the concentrator and were refracted towards the exit aperture. The refractive index of the concentrator was set at 1.50. As mirrored in the experiment which will be described in the following Section 4, a $1 \mathrm{~mm}$ layer of index matching gel is placed between the concentrator and the detector. The index of refraction is set to 1.4418 as stated in the Sylgard 184 adhesive gel datasheet.

Optical efficiency describes the percentage of rays reaching the exit of those rays that passed through the entrance; hence rays that arrive from the side are ignored. Thus a box is placed around the concentrator to eliminate incidence from the sides. A hole was created at the top-centre of the box which has the same coordinates as the cap to provide optimum fitting.

The simulation is run with the box with different angles of incidence. This is due to the entrance aperture of the concentrator not being perfectly flat, shade was introduced onto the entrance aperture when the concentrator and the box were tilted. As a result the power source was rotated instead to prevent this undesirable shade and the box was lowered to free the entire entrance aperture as shown in Figure 5. 
The position of the source was calculated for each tilt angle to make sure that the

256

257

258

259

260

261

262

263

264

265

266

267

268

269

270

271

272

273

274

275

276

277 concentrator is entirely covered with rays and a distance of $350 \mathrm{~mm}$ between the concentrator and the source is kept. However due to the complex design of the entrance aperture small parts of the side profiles are exposed to light when the source is tilted. This introduces additional rays from the side and as a result increases the concentration gain at larger tilt angles.

\subsubsection{Results and Discussions}

\subsubsection{Flux distribution}

During the simulations, flux distribution analysis was carried out showing that the concentrated rays are not distributed uniformly on the receiver. The flux distribution on the solar cell under direct irradiance is presented in Figure 6. It can be seen that the illumination distribution at an angle of incidence of $0^{\circ}$ along both axes gives a strong pattern of concentrated rays. It can also be observed that many rays are concentrated onto the edge of the receiver. Therefore during the assembly process of the concentrator and the solar cell, the area of the bottom part of the concentrator should not be covered with the index matching gel. Otherwise it would lead to an increased escaping of rays as the index matching gel has a higher index of refraction than air. When the angle of incidence increases up to $\pm 40^{\circ}$ along the z-axis, the pattern of the concentrated rays becomes less strong as can be seen in the comparison between Figures 6(a) and 6(b). This is due to the fact that when the angle of incidence is $\pm 40^{\circ}, 80 \%$ fewer rays reach the exit aperture. When the angle of incidence is large along both axes, more rays are focussed on the edge of the receiver as can be seen in Figure 6(c).

Figure 6: Flux distribution on the receiver under direct irradiance at angles of incidence of: (a) $0^{\circ}$ along both axes; (b) $40^{\circ}$ along the $\mathrm{x}$-axis, and (c) $40^{\circ}$ along the $\mathrm{x}$-axis and $23^{\circ}$ along the z-axis.

However, since the rays are not ideally parallel and the irradiance varies constantly, the pattern of concentrated rays on the receiver also changes constantly reducing the risk of 
hot spots. Nevertheless, the effect of the non-uniform flux distribution on the PV material caused by the concentrator requires further investigation.

\subsubsection{Optical concentration gain}

The optical concentration gain was calculated by multiplying the optical efficiency with the geometrical concentration gain [28]. The result for the optical concentration gain is expected to be slightly below the geometrical gain due to losses of rays at side profiles and due to reflection at the entrance aperture. The concentrator is designed to have a half acceptance angle of $\pm 40^{\circ}$ along the $\mathrm{z}$-axis and $\pm 30^{\circ}$ along the $\mathrm{x}$-axis. Thus the optical concentration gain is a function of angle of incidence. It is expected to have a flat gain within the designed acceptance angles and to experience a sharp drop outside those. The concentration gain is smaller with a larger the field of view [35]. Hence the gain along the xaxis (where the acceptance angle is smaller) is expected to be slightly higher compared to the gain along the z-axis. The obtained optical concentration gain is shown in Figure 7.

Figure 7: Simulation result for the optical concentration gain under direct light.

The optical concentration gain at $0^{\circ}$ along the $\mathrm{x}$ - and the $\mathrm{z}$-axis is $6.01 \%$ and $8.3 \%$ lower when compared to the geometric concentration gain respectively. This is due to reflection of rays at the surface of the entrance aperture and rays escaping through the side profile. As expected, the optical concentration gain is slightly higher along the $\mathrm{x}$-axis with the narrower field of view than along the z-axis. For tilt angles between $\pm 20^{\circ}$ the optical concentration gain along the $\mathrm{x}$-axis is relatively flat with a slight increase between $\pm 15^{\circ}$ and $\pm 20^{\circ}$. This is because parts of the side profiles are being exposed to the light at these angles. The gain starts decreasing gradually when the tilt angle is between $\pm 20^{\circ}$ and $\pm 25^{\circ}$. After $\pm 25^{\circ}$, the optical concentration gain along the $\mathrm{x}$-axis reduces greatly, thus the acceptance angle is smaller than designed. This is due to the loss of rays through the side profile at larger angles of incidence. When the angle of incidence at the entrance aperture increases, more rays are refracted outwards, instead of being reflected towards the exit aperture, this is shown in Figure 8. At a $\pm 30^{\circ}$ tilt angle, the rays which hit the side profile are reflected towards the detector. At $\pm 60^{\circ}$ tilt angle the angle of incidence at the side profile is smaller and the rays are either refracted outwards or are reflected to the opposite side profile and escaped. 
However inside an LCPV module which comprises of an array of concentrators, these rays would enter the other concentrators and contribute to the overall electrical output.

Figure 8: Ray path at large tilt angles, where: (a) at $30^{\circ}$ tilt angle, and (b) at $60^{\circ}$ tilt angle.

The concentration gain along the z-axis is ideally flat for angles of incidence between $\pm 25^{\circ}$. After $\pm 30^{\circ}$, it experiences a sharp drop unlike the expected result which was at $\pm 40^{\circ}$ for the same reasons as discussed before. However the concentration gain at the maximum acceptance angles is still greater than 1. Moreover the concentrator accepts sun light until $\pm 50^{\circ}$ along the x-plane and until $\pm 60^{\circ}$ along the z-plane even though it is designed for $\pm 30^{\circ}$ and $\pm 40^{\circ}$ respectively. The disagreements between the expected and received results are due to the fact that the geometrical properties of the concentrator designed in MATLAB were defined to maximise the output at each angle of rotation around its axis of symmetry. However the information of what happens between the steps is not given, which leads to the unexpected results.

\subsection{Diffuse light simulation}

\subsubsection{Method}

Figure 9 shows the diffuse light simulation setup. In order to obtain the optical concentration gain of the concentrator under diffuse light, a light source which generates rays coming from all directions is needed. As any object can be turned into a light source, a dome with a thickness of $1 \mathrm{~mm}$ and a $380 \mathrm{~mm}$ radius was created using AutoCAD. The radius corresponds to the distance between light source and concentrator during the direct light simulations. The dome was created by revolving a circle section around an axis instead of using the dome function implemented in AutoCAD, which consists of planar sections. Thus none of the emitted rays are parallel to each other which enhances the similarity between the simulations and real diffuse light conditions. Likewise for the direct light simulation the light source was set to emit 1 million rays at a power of $1000 \mathrm{~W}$. The concentrator, the layer of index matching gel and the detector are placed at the edge of the dome. This gives a $350 \mathrm{~mm}$ distance between the dome and the concentrator as with the direct light experiments.

Figure 9: Diffuse light simulation setup. 
Considering that diffuse light is not directional, the optical concentration gain for the

356

357

358

359

360

361

362

363

364

365

366

367 diffuse light is not a function of the incident angle of light. Therefore the concentration ratio for diffuse light is determined only at $0^{\circ}$. When rays escape through the side profile of a concentrator or are reflected at its entrance aperture, they enter other concentrators inside the LCPV module. Consequently those rays are also defined as diffuse light and need to be considered in the definition of optical concentration gain. For this reason the side profiles of the concentrator are not covered with a box unlike during direct light simulations. The total power at the detector is obtained with and without the concentrator. The optical concentration gain is defined in the same way as the opto-electronic gain, $C_{\text {opt-el }}$, i.e. by dividing the total power at the detector with the concentrator $P_{\text {with-con }}$ by the one obtained without the concentrator, $P_{\text {without-con }}[36]$ (see Equation (1)).

$$
C_{\text {opt-el }}=\frac{P_{\text {with-con }}}{P_{\text {without }- \text { con }}}
$$

\subsubsection{Results and Discussions}

\subsubsection{Flux distribution}

The illumination under diffuse light does not have strong points of concentrated rays as can be seen in Figure 10. Furthermore, as diffuse irradiance is not directional, the rays enter the concentrator at different angles of incidence. Consequently the pattern of the concentrated rays under diffuse light changes constantly and does not lead to strong concentration pattern unlike the case of under direct irradiance.

Figure 10: Flux distribution on the receiver under diffuse irradiance.

\subsubsection{Optical Concentration Gain}

Although additional rays come from the side profile of the concentrator, the optical concentration gain is distinctly lower than for direct light simulations achieving an optical concentration gain of 1.94. The optical concentration gain for direct light is 4.66 and thus 
higher by factor 2.4. This is because the concentrator design was optimised for direct irradiance and the field of view is therefore limited.

Using the optical concentration gain definition, an optical efficiency of $41 \%$ was calculated. However this includes rays coming from the sides and not only through the entrance aperture as the definition describes. To be able to compare the optical efficiency with other proposed concentrators for BICPV systems, the simulation was repeated with a box covering its sides. This results in an optical efficiency of 35\%. The SEH concentrator proposed by Sellami and Mallick [31] achieved an optical efficiency between 27\% and 41\% depending on the height. It is observed that the optical efficiency of RADTIRC for diffuse light concentration is also within the same range as the SEH concentrator. Since the optical efficiency for direct light is distinctly better, reaching 95\%, it emphasises that the concentrator was optimised for direct irradiation. For a better performance of the concentrator under diffuse light, a larger entrance aperture as well as a larger acceptance angle is needed.

The results from diffuse simulation shows that the output is nearly doubled compared to its non-concentrating counterpart; hence diffuse irradiation can contribute significantly to the electrical output of an RADTIRC-PV module.

\section{Experimental performance analysis}

In order to validate the simulation results, the performance of the concentrator needs to be obtained experimentally. Therefore an RADTIRC-PV device and a non-concentrating PV cell device were fabricated.

\subsection{Fabrication of RADTIRC-PV device}

The concentrator was fabricated by UK Optical Plastic Limited using injection moulding. The material used is Altuglas V825T, which is a variation of PMMA. It has an index of refraction of 1.49 and a transmittance of $92 \%$ [37]. After the moulding process, there are residual marks from excess plastic on the concentrator which need to be polished. It has been experimentally proven by the lead author that polished concentrators have a better optical performance than unpolished concentrators. Thus only results from the polished concentrator are included for comparison.

The silicon solar cells are provided by Solar Capture Technologies Ltd and are Laser Grooved Buried Contact (LGBC) cells designed for LCPV applications with concentration 
ratios below 10. A cell efficiency of $14.9 \%$ was determined experimentally. According to the data sheet the cell size is $100 \mathrm{~mm}^{2}$. However following measurements presented in Figure 11, it was found that there is a deviation of $13 \%$ from the provided data. The values are displayed in $\mathrm{mm}$.

Figure 11: Dimensions of the solar cell, where (a) the schematic provided by the company, and (b) the actual measurement.

Because the cells were cut from one wafer, the cells used for fabrication of the samples are expected to have deviations within the scope due to cell manufacturing errors. In case the active area of the PV device is smaller than the area of the cell used for the CPV device, it will result in a higher opto-electronic gain. On the other hand, in the case of the active area of the cell used being smaller than the exit aperture of the concentrator, this will lead to optical losses and a lower opto-electronic gain. This deviation will be considered when experimental results are evaluated.

Two LGBC cells were tabbed with a flat lead free wire of $0.1 \mathrm{~mm}$ thickness and $1 \mathrm{~mm}$ width. A soldering iron with a power of $81 \mathrm{~W}$ and at a working temperature of $350^{\circ} \mathrm{C}$ was used. Because at these temperatures damage to solar cells can occur, the soldering iron was applied for a short period of time. The tabbing wire is placed on the edge of the cell to maximise the active area of the cell.

Each tabbed cell is attached to a $70 \mathrm{~mm} \times 70 \mathrm{~mm}$ x $40 \mathrm{~mm}$ glass plate using superglue. In order to prevent the encapsulation material for the concentrators from overflowing, a foam frame was attached. The foam legs beneath the glass plate enhance cooling of the cells during experiments (see Figure 12(a)).

$$
\begin{gathered}
\text { Figure 12: Fabricating the samples: (a) non-concentrating PV cell, and (b) RADTIRC-PV } \\
\text { device. }
\end{gathered}
$$

The RADTIRC concentrator is attached by using an encapsulation material which functions simultaneously as an adhesive and as an index matching gel. Sylgard-184 Silicon Elastomer has an index of refraction of 1.4225 (at $632.8 \mathrm{~nm}$ wavelength) and provides excellent transmission [38]. As the refractive index of the concentrator is 1.49 [37] and of the silicon is 3.882 (at $632.8 \mathrm{~nm}$ wavelength) [39], the refractive index of the encapsulation material it is not a perfect fit. Preferably the index matching gel should have an index of 
453 refraction within the refractive indices of the two materials. Therefore optical losses due to reflection at the borders are expected.

The Sylgard-184 is a two part adhesive. It is mixed in a 10:1 weight ratio and stirred for 10 minutes. Before applying the silicon on the cell a liquid primer (Dow Corning Primer 92-023) is applied for a better adhesion between the silicon and the cell. Only one small drop is used on the cell to create a very thin layer. After leaving the primer to dry for $10 \mathrm{~min}$, index matching gel is placed on the solar cell and spread over the surface coating the cell and the glass around it. As discussed in Section 3, it is important that the sides of the bottom part of the concentrator are not covered to minimise rays escaping at that specific part of the concentrator. During the stirring of the gel, air is introduced into the solution. Placing the prepared cells with the silicon in a vacuum chamber for 15 minutes enables any air bubbles to evaporate.

When the concentrator is placed on the cells, it tends to slide due to the low viscosity of the silicon. Additional precision is required to prevent misalignment between cell and concentrator which can lead to significant optical losses (see Figure 12(b)). Furthermore air bubbles must not be introduced between the concentrator and the cell. The sample is left for curing at room temperature for 48 hours.

\subsection{Experimental characterisation under direct light}

\subsubsection{Experimental setup}

Direct light experiments were carried out indoors under the radiation of a sun simulator. Electrical readings were taken from a PV cell with and without the concentrator. The experimental setup is shown in Figure 13, and the main characteristics of the components used in the experimental setup are presented in Table 1.

Figure 13: Experimental setup.

Table 1: Main characteristics of the components used in indoor experiments.

The Oriel ${ }^{\circledR}$ Sol3A $\mathrm{A}^{\mathrm{TM}}$ Class AAA Solar Simulators [40] with a model number 94083A was used as a light source. The AAA class defines that the solar simulator has a 
spectral performance match of between 0.75 to 1.25 times of the ideal percentage. Both the temporal instability and the non-uniformity of the irradiance are lower than $2 \%$. Within these limits, the ozone free xenon short arc lamp emits a spectrum that is comparable to a $5800 \mathrm{~K}$ blackbody and has a uniform irradiance of $203.2 \mathrm{~mm}^{2}$ at a working distance of 365-395 mm [40]. An air mass filter of $1.5 \mathrm{G}$ according to the standard test conditions (STC) is integrated into the simulator. The output of the irradiance is adjustable between 0.1 and 1 sun whereas 1 sun equals to $1000 \mathrm{~W} / \mathrm{m}^{2}$ at $25^{\circ} \mathrm{C}$ and $1.5 \mathrm{G}$.

A Model 2440 5A Source Meter from Keithley instruments is used together with Keithley Lab Tracer 2.0 software which is a current - voltage (I-V) curve tracing application provided by the supplier. The Source Meter is a highly stable multimeter which can function either as a voltage/current source or a voltage/current/resistance meter and I-V characterisation is a typical application. The Source Meter transmits 1700 readings per second, the readings are taken using a four wire set up which is more accurate than two wire set up [42]. The irradiance of the sun simulator was adjusted to be $1000 \mathrm{~W} / \mathrm{m}^{2}$ according to STC and was measured during the experiment using the Oriel PV Reference Cell System Model 91150V [43]. This system consists of a $400 \mathrm{~mm}^{2}$ monocrystalline silicon photovoltaic cell and a type $\mathrm{K}$ thermocouple. As a result the irradiance and the cell temperature are measured simultaneously.

I-V curve tracing was carried out for the single cell device and for the cell with the concentrator, at angles of incidence between $0^{\circ}$ and $60^{\circ}$. A designed and manufactured variable slope meter was used to tilt the device in $5^{\circ}$ steps along both axes and the inclination was measured by a digital tilt meter. The room temperature was maintained at $25^{\circ} \mathrm{C}$.

\subsubsection{Results and discussions}

For each tilt angle the short circuit current, $I_{S C}$, open circuit voltage, $V_{O C}$, maximum power point current, $I_{M P P}$, maximum power point voltage, $V_{M P P}$ and maximum power point power, $P_{M P P}$ were recorded. An I-V curve and a power - voltage $(\mathrm{P}-\mathrm{V})$ curve at a $0^{\circ}$ tilt angle of the RADTIRC-PV device and the non-concentrating PV cell are shown in Figure 14.

Figure 14: The short circuit current and the power generated from the concentrating and nonconcentrating PV devices. 
Since short circuit current is proportional to irradiance, it was increased by a factor of 4.47 due to the concentration of light on the solar cell area. The voltage was increased slightly which leads to an increased maximum power by a factor of 5.1. The fill factor (FF), which describes how well the $I-V$ curve approaches a rectangular shape was improved from 0.76 to 0.78 . It was calculated by using Equation (2) [44]:

$$
F F=\frac{P_{M P P}}{V_{O C} \times I_{S C}}
$$

524

525

526

527

528

529

530

531

532

533

534

535

536

537

538

539

540

541

542

543

544

545

546

547

548

549

550

The angular response is the performance of the system at different angles of incidence. The opto-electronic gain is determined at tilt angles between $0^{\circ}$ and $\pm 60^{\circ}$ in order to compare the experimentally determined angular response of the concentrator to the simulation result. The opto-electronic gain is expected to be lower than the optical gain due to optical and electrical losses and to differ even more from the ideal angular response. The concentration gain for angles of incidence along the z-axis is expected to be slightly higher than when varied along for the $\mathrm{x}$-axis as discussed for the simulation results in Section 3 . The opto-electronic gain as a function of angle of incidence is shown in Figure 15, as is compared with the optical concentration gain obtained from the simulations.

36

\section{Figure 15: Optical gain of the RADTIRC as a function of the angle of incidence.}

7

In contrast to the results from the optical concentration gain, the opto-electronic gain has similar results on both the z-axis and $x$-axis at angles of incidence between $\pm 20^{\circ}$. The difference of $2.5 \%$ as determined from the simulation was due to the manufacturing inaccuracy. The concentration gain at angles greater than $\pm 20^{\circ}$ is higher along the z-plane due to the larger acceptance angle.

It can be observed that the opto-electronic gain is lower than the optical concentration gain. The deviation increases with the angle of incidence, hence reduces the overall performance of the concentrator. The reduction in gain is caused by various manufacturing errors. Firstly to be able to manufacture the device the amount of points generated in MATLAB was reduced, in order to simplify the file for injection moulding. Thus the accuracy of the surface of the concentrator was reduced. As the design is relatively complicated, a very thin layer of additional or missing material can lead to different diffraction and reflection of rays which again leads to optical losses. Electrical losses due to 
551

552

553

554

555

556

557

558

559

560

561

562

563

564

565

566

567

568

569

570

571

572

573

574

575

576

577

578

579

580

581

582

583

584

the quality of the tabbing and the connections between tabbing wires and the $I-V$ curve tracer need to be considered. Also the accuracy of orientation of the concentrator with regards to the tilt angle is limited. A further error is the misalignment of the concentrator on the cell which is shown in Figure 16(a).

This can be due to a reduced active area of the cell, which can be caused by the tabbing wire being too wide or the imprecise size of the solar cell. The moulding technique itself introduces further errors. Firstly small particles are included inside the concentrator as shown in Figure 16(b) which leads to refraction or reflection of rays at the particle. Secondly since the polymer is injected into the mould, the solidification process couldcreate multiple thin layers that has difference refractive indices which can lead to a change of the ray's path.

The losses along the $\mathrm{x}$-axis are higher than along the z-axis. This is due to the polishing of moulding marks on the two sides as discussed in Section 3 as those areas are crucial for the reflection of rays, hence this leads to optical losses. In conclusion, the reduction in gain between the simulation result and the experimental result along the $\mathrm{z}$-axis is $1.9 \%$ and along the $\mathrm{x}$-axis is $4.2 \%$ at normal incidence.

$$
\begin{aligned}
& \text { Figure 16: Errors introduced in the device, showing: (a) misalignment between the exit } \\
& \text { aperture and the solar PV cell that occurred during the assembly process, and (b) small } \\
& \text { particles introduced in the RADTIRC during the manufacturing process. }
\end{aligned}
$$

\subsection{Diffuse light experiments}

\subsubsection{Experimental setup}

The performance analysis of the concentrator under diffuse light was carried out outdoors, as the necessary equipment to reproduce diffuse light conditions indoors is not available. The experiments (shown in Figure 17) were carried out within the university area on a roof top which is surrounded by other buildings. $\left(55.866^{\circ} \mathrm{N}, 4.250^{\circ} \mathrm{W}\right)$ The set up includes the RADTIRC-PV device, a non-concentrating PV cell device, a pyranometer, an inclinometer, a thermometer and 3 multimeters.

Figure 17: Experimental setup for outdoor diffuse light experiments. 

were connected to a multimeter. With a thermo-couple thermometer, a temperature of $13^{\circ} \mathrm{C}$ was recorded. The slope of the location used is $0.5^{\circ}$ towards south measured with a digital slope meter.

An Apogee SP-110 pyranometer [45] was used to measure the global irradiance. The calibration uncertainty is given with $\pm 5 \%$ which was proven experimentally under the sun simulator. The field of view is $180^{\circ}$. It is a silicon cell pyranometer and sensible for shortwave radiation between $320 \mathrm{~nm}$ and $1120 \mathrm{~nm}$. The voltage signal of the sensor is directly proportional to total shortwave radiation. Therefore the signal was taken in $\mathrm{mV}$ with a multimeter and converted into irradiance using the standard calibration factor, which is exactly $5 \mathrm{Wm}^{-2}$ per $1 \mathrm{mV}$.

However the Apogee SP series pyranometers are calibrated under electrical lamps reproducing clear sky conditions and an air mass of $1.5 \mathrm{G}$. Referring to the datasheet [45], spectral errors might occur when the device is used under different conditions than calibrated due to the limited spectral response of the silicon cell. This is the case in this experiment, as the sky was overcast. The amount of diffuse radiation at the particular time is calculated in the next paragraph. The solar altitude angle at the time of the experiment gave a spectral error of $-1 \%$ [45]. Further error of approximately $1 \%$ is due to the cable orientation error, which needed to face the magnetic north [45]. Thus an overall accuracy of 5\% is given [45].

The exact amounts of direct and diffuse light can be calculated when the sun angle is 606 known, which can either be determined manually or using the software tools provided on websites like $w w w$.sonnenverlauf.de. Depending on how overcast the day is, a different factor $k_{T}$ will need to be determined using Equation (3) [46], where $E_{G, h o r}$ is the measured global irradiance at the horizontal plane, $E_{0}$ is the solar constant of $1361 \mathrm{Wm}^{-2}$ [46] and $\gamma_{S}$, the solar altitude angle at the particular time. When the $k_{T}$ is 0 , it represents an overcast day while when the $k_{T}$ is 1 , it represents a clear day.

612

$$
k_{T}=\frac{E_{G, h o r}}{E_{0} \times \sin \gamma_{S}}
$$
particular time, a $k_{T}$ factor of 0.145 was calculated which proves that the amount of diffuse 
616

617

618

619

620

621

622

623

624

625

626

627

628

629

630

631

632

633

634

635

636

637

638

639

640

641

642

643

644

645

646

647

light was high during the experiments. With this value, the diffuse irradiance at the horizontal plane can be calculated by using Equation (4) [46].

$E_{\text {diff }, \text { hor }}=E_{G, \text { hor }} \times\left(1.020-0.254 \times k_{T}+0.0123 \times \sin \gamma_{S}\right) \quad$ for $\quad k_{T} \leq 0.3$

9

For the values given in Equation (3), a diffuse irradiance of $69.62 \mathrm{Wm}^{-2}$ was calculated. This means that at the moment of the experiment, direct irradiance made up 1.3\% of global irradiance. For a comparison meteorological data from the Met Office Glasgow were consulted, where readings came from a site which is located approximately $18 \mathrm{~km}$ west of the location used for the experiment. The data from the Met station for the same hour was $78.9 \mathrm{Wm}^{-2}$ and have therefore an amount of $1.6 \%$ of direct light irradiance.

\subsubsection{Results and Discussions}

The obtained opto-electronic gain is 2.13. This compared with the simulation result which is 1.94 gives a difference of $9.8 \%$. For outdoor experiments there are many factors influencing the concentration ratio which need to be considered. Firstly, the amount of direct light increases the concentration ratio. $1.2 \%$ of direct light is concentrated about 2.5 times more than the diffuse light and as a result direct light makes up about 3\% of the overall concentrated light which reaches the solar cell.

Secondly, the site where the experiments were carried out is surrounded by buildings, which have a high reflectivity due to the outer coating and window glass. The surrounding of the experimental location is shown in Figure 20. The concentrator accepts light not only through the exit aperture but also from the sides, which increases the active area in comparison to the flat solar cell. The estimation of reflectivity of the buildings is based on the reflectivity values of the material and the colour. The reflectivity of fairly new concrete is taken between $30 \%$ and $40 \%$ [47], the reflectivity of glass as $7 \%$ [48] and the reflectivity of overall painting as $80 \%$ according to the light reflectance value (LRV) scale [49].

Figure 18: Location surrounding for outdoor diffuse light experiment: (a) back side; (b) right side, and (c) left side. 
To validate that the opto-electronic concentration gain was increased by additional light reflected from the buildings, the simulations were repeated and the coating of the dome was set to $50 \%$ reflectivity. This increased the concentration of rays by $5 \%$ whereas the amount of rays on the flat solar cell stays the same. The fact that the detector without the concentrator does not receive more rays shows that the reflectance from the top of the dome is not significant. Therefore we can assume that the simulation is suitable to simulate the reflectance of the buildings around the experimental site. With a dome reflectivity of $50 \%$, the optical concentration gain was increased to 2.03. That shows the influence of reflection on the performance of the concentrator.

Another influencing factor is the ground reflection. Ground reflection is not considered for horizontal surfaces thus for the solar cell device but for tilted surfaces. The side profiles of the concentrator (see Figure 2(c)) represent a tilted surface which accepts 660 light.

The irradiance reflected onto a tilted surface is calculated using Equation (5) [46]. Albedo $\mathrm{A}$ is constant which depends on the type of surface, $\gamma_{t}$ is the angle of the side profile and $E_{G, h o r}$ is the global irradiance on a horizontal plane.

664

$$
E_{r e f, t i l t}=E_{G, h o r} \times \mathrm{A} \times 0.5 \times\left(1-\cos \left(\gamma_{t}\right)\right)
$$

665

666

667

668

669

670

As the surface is a mixture of grass, concrete, woods and metal, an $\mathrm{A}=0.2$ was used as recommended for unknown surfaces [46]. The global irradiance is $70.5 \mathrm{Wm}^{-2}$. The angle of the side profile in Figure 2(c) measured clockwise from the horizontal [46] is found to be approximately $105^{\circ}$. The calculated ground reflected irradiance of $8.87 \mathrm{Wm}^{-2}$ is an additional irradiance, which acts only on the concentrator and not on the solar cell. This further explains the difference between the experimentally determined and simulated concentration gain.

\section{Conclusion}

The performances of the RADTIRC under direct and diffuse light conditions were investigated thoroughly in this paper. The optical concentrator for LCPV systems has a geometrical concentration gain of 4.969 and two half acceptance angles of $\pm 40^{\circ}$ along the $\mathrm{z}$ axis and $\pm 30^{\circ}$ along the $\mathrm{x}$ - axis.

Simulation work was carried out to determine the optical concentration gain as well as the acceptance angle of the concentrator under direct and diffuse irradiance. Using a ray 
681

682

683

684

685

686

687

688

689

690

691

692

693

694

695

696

697

698

699

700

701

702

703

704

705

706

707

708

709

710

711

712

713

714

715

tracing technique, an optical concentration gain of 4.66 was determined under direct irradiance. It was shown that the concentrator has a good angular response within the designed acceptance angles. The optical concentration gain under diffuse irradiance is 1.94 and does not depend on the angle of incidence of the rays. Furthermore, it has been observed that the flux distribution on the cell is not uniform. The degree of non-uniformity and its effect on the solar cell material requires further investigation.

The simulation results were validated experimentally, indoor under direct light conditions and outdoor under diffuse light conditions. The results pertaining to the indoor test are in good agreement with the simulation results, a deviation in concentration gain of $4.2 \%$ was noted. The experimentally determined angular response of the concentrator shows a reduced concentration gain when the angle of incidence is increased. Optical and electrical losses have been identified as reasons for the deviations between the simulation and experimental results.

It can be concluded that the RADTIRC has the ability to improve the performance of BICPV systems by increasing the electrical output when compared to a non-concentrating PV system with the same volume of PV material. Savings in PV material, increased natural illumination and heat generation make the implementation BIPV systems more attractive. Therefore the BICPV technology can contribute to the EU target of more carbon neutral buildings, an increased technology efficiency and more renewable energy generation.

The next research step is the investigation of cooling possibilities of the system in order to provide a constant solar cell temperature. The active cooling by either air or water utilises the co-generated heat from the PV effect which can be used within the building for heating, hot water or even cooling. Another main advantage is the natural illumination of the rooms under a LCPV skylight due to the transparency of the concentrators. This can lead to a reduction in electricity consumption for illumination purposes of buildings.

\section{References}

[1] Weart S. The Discovery of Global Warming. Revised Ed. USA: Harvard University Press; 2015.

[2] Quaschning V. 2013. Weltweite Kohlen-dioxid-emissionen und -konzentration in der Atmosphäre. Available from http://www.volkerquaschning.de/datserv/CO2/index.php. Last accessed on 27 Oct 2015.

[3] European Council. 2030 Climate and Energy Policies Framework. 2014.

[4] Bergamaschi L, Holmes I, Lawson R. Making sense of the numbers : What does the 
Commission's 30\% energy efficiency target by 2030 mean and is it enough? London, UK: 2014.

[5] IEA. Technology Roadmap: Energy Efficient Building Envelope. Paris, France: 2013.

[6] Zero Carbon Hub. Zero Carbon Homes and Nearly Zero Energy Buildings: UK Building Regulations and EU Directives. 2014.

[7] Wirth H. Recent Facts about Photovoltaics in Germany. Germany: 2015.

[8] Photovoltaik.org. 2015. PV Price in 2015. Available from http://www.photovoltaik.org/wirtschaftlichkeit/photovoltaik-preise. Last accessed on 03 Nov 2015.

[9] BDEW. 2014. Anteil Erneuerbarer Energien am Stromverbrauch steigt im ersten Quartal auf Rekordwert von 27 Prozent. Available from https://www.bdew.de/internet.nsf/id/20140509-pi-bdew-veroeffentlicht-erstequartalszahlen-zu-erneuerbaren-energien-de?open\&ccm=9000 2015.

[10] BMWi. Gesetz für den Ausbau erneuerbarer Energien (Erneuerbare - Energien Gesetz - EEG 2014). 2014.

[11] Abu-Bakar SH, Muhammad-Sukki F, Freier D, Ramirez-Iniguez R, Mallick TK, Munir AB, et al. Optimisation of the performance of a novel rotationally asymmetrical optical concentrator design for building integrated photovoltaic system. Energy 2015;90:1033-45.

[12] NREL. 2015. National Center for Photovoltaics. Available from http://www.nrel.gov/ncpv/index.html. Last accessed on 10 June 2015.

[13] Green MA, Emery K, Hishikawa Y, Warta W, Dunlop ED. Solar cell efficiency tables (version 47). Prog Photovolt: Res Appl 2016;24:3-11.

[14] Dimroth F, Grave M, Beutel P, Fiedeler U, Karcher C, Tibbits TND, et al. Wafer bonded four-junction $\mathrm{GaInP} / \mathrm{GaAs} / / \mathrm{GaInAsP} / \mathrm{GaInAs}$ concentrator solar cells with 44.7\% efficiency. Progress in Photovoltaics: Research and Applications 2014;22:27782.

[15] Muhammad-Sukki F, Abu-Bakar SH, Ramirez-Iniguez R, McMeekin SG, Stewart BG, Sarmah N, et al. Mirror symmetrical dielectric totally internally reflecting concentrator for building integrated photovoltaic systems. Applied Energy 2014;113:32-40.

[16] TMR. Building Integrated Photovoltaics (BIPV) Market: Global Industry Analysis, Size, Share, Growth, Trends and Forecast, 2013 - 2019. 2014.

[17] Norton B, Eames PC, Mallick TK, Huang MJ, McCormack SJ, Mondol JD, et al. Enhancing the performance of building integrated photovoltaics. Solar Energy 2011;85:1629-64.

[18] Tripathy M, Sadhu PK, Panda SK. A critical review on building integrated photovoltaic products and their applications. Renewable and Sustainable Energy Reviews 2016;61:451-65.

[19] Azadian F, Radzi MAM. A general approach toward building integrated photovoltaic systems and its implementation barriers: A review. Renewable and Sustainable Energy Reviews 2013;22:527-38.

[20] Quesada G, Rousse D, Dutil Y, Badache M, Hallé S. A comprehensive review of solar facades. Opaque solar facades. Renewable and Sustainable Energy Reviews 
2012;16:2820-32.

[21] Baig H, Sellami N, Chemisana D, Rosell J, Mallick TK. Performance analysis of a dielectric based 3D building integrated concentrating photovoltaic system. Solar Energy 2014;103:525-40.

[22] Mallick TK, Eames PC, Hyde TJ, Norton B. The design and experimental characterisation of an asymmetric compound parabolic photovoltaic concentrator for building façade integration in the UK. Solar Energy 2004;77:319-27.

[23] Zacharopoulos A, Eames P., McLarnon D, Norton B. Linear Dielectric Non-Imaging Concentrating Covers For PV Integrated Building Facades. Solar Energy 2000;68:439-52.

[24] Sarmah N, Mallick TK. Design, fabrication and outdoor performance analysis of a low concentrating photovoltaic system. Solar Energy 2015;112:361-72.

[25] Li G, Pei G, Su Y, Ji J, Riffat SB. Experiment and simulation study on the flux distribution of lens-walled compound parabolic concentrator compared with mirror compound parabolic concentrator. Energy 2013;58:398-403.

[26] Abu-Bakar SH, Muhammad-Sukki F, Freier D, Ramirez-Iniguez R, Mallick TK, Munir AB, et al. Performance analysis of a novel rotationally asymmetrical compound parabolic concentrator. Applied Energy 2015;154:221-31.

[27] Muhammad-Sukki F, Ramirez-iniguez R, McMeekin SG, Stewart BG, Clive B. Solar concentrators in Malaysia: Towards the development of low cost solar photovoltaic systems. Jurnal Teknologi 2011;54:289-98.

[28] Sellami N, Mallick TK, McNeil DA. Optical characterisation of 3-D static solar concentrator. Energy Conversion and Management 2012;64:579-86.

[29] Muhammad-Sukki F, Abu-Bakar SH, Ramirez-Iniguez R, McMeekin SG, Stewart BG, Munir AB, et al. Performance analysis of a mirror symmetrical dielectric totally internally reflecting concentrator for building integrated photovoltaic systems. Applied Energy 2013;111:288-99.

[30] Ramirez-iniguez R, Muhammad-Sukki F, McMeekin SG, Stewart BG. Optical element. Patent No. 2497942, 2014.

[31] Sellami N, Mallick TK. Optical characterisation and optimisation of a static Window Integrated Concentrating Photovoltaic system. Solar Energy 2013;91:273-82.

[32] Welford WT, Winston R. High Collection Nonimaging Optics. Academic Press; 1989.

[33] Zemax LLC. Getting Started Using OpticStudio 2015.

[34] Winston R, Miñano JC, Benítez P, Shatz N, Bortz JC. Nonimaging Optics. USA: Academic Press; 2005.

[35] Rabl A. Comparison of solar concentrators. Solar Energy 1976;18:93-111.

[36] Ning X, Winston R, O'Gallagher J. Dielectric totally internally reflecting concentrators. Applied Optics 1987;26:300-5.

[37] Boedeker Plastics Inc. 2015. Acrylic PMMA (Polymethyl-Methacrylate) Specifications. Available from http://www.boedeker.com/acryl_p.htm. Last accessed on 01 March 2015.

[38] Shenzhen Hong Ye Jie Technology Co Ltd. 2015. Sylgard 184 Silicone Elastomer Kit. Available from http://uk.alibaba.com/product/737520138-sylgard-184-siliconeelastomer-kit.html. Last accessed on 07 July 2015. 
804

805

806

807

808

809

810

811

812

813

814

815

816

817

818

819

820

821

822

[39] Edwards DF, Ochoa E. Infrared refractive index of silicon. Applied Optics 1980;19:4130-1.

[40] Oriel Instruments. Oriel Sol3A ${ }^{\mathrm{TM}}$ Class AAA Solar Simulators. USA: 2007.

[41] Universal Supplies Ltd. 2016. Digital Angle Gauge Protractor Inclinometer. Available from http://www.ebay.co.uk/itm/Digital-Angle-Gauge-Protractor-Inclinometer-PouchNEW-/250570182600. Last accessed on 04 May 2016.

[42] Keithley Instruments Inc. Series 2400 SourceMeter SMU Instruments. 2016.

[43] Newport. The Newport Resource. USA: 2011.

[44] Qi B, Wang J. Fill factor in organic solar cells. Physical Chemistry Chemical Physics : PCCP 2013;15:8972-82.

[45] Apogee Instrument. Owner's Manual: Pyranometer. 2014.

[46] Volker Quaschning. Understanding Renewable Energy Systems. Earthscan; 2004.

[47] ACPA. Albedo: A measure of pavement surface reflectance. USA: 2002.

[48] Efficient Windows Collaborative. 2015. Reflectance. Available from http://www.commercialwindows.org/reflectance.php. Last accessed on 27 Oct 2015.

[49] Sawaya L, Sawaya AR. 2005. LRV Light Reflectance Value of Paint Colors. Available from http://thelandofcolor.com/lrv-light-reflectance-value-of-paint-colors/. Last accessed on 27 Oct 2015. 


\section{Figure description}

\begin{tabular}{|c|c|c|}
\hline Figure & Description & $\begin{array}{l}\text { Proposed size } \\
\text { (width) }\end{array}$ \\
\hline 1 & $\begin{array}{l}\text { Generation of an RADTIRC design from a series of 2D DTIRC } \\
\text { design [15]. }\end{array}$ & $90 \mathrm{~mm}$ \\
\hline 2 & RADTIRC [29]. & $140 \mathrm{~mm}$ \\
\hline 3 & $\begin{array}{l}\text { Flow chart to carry out the direct light simulation: (a) determining the } \\
\text { flux at the entrance aperture, and (b) determining the flux at the exit } \\
\text { aperture of the RADTIRC. }\end{array}$ & $\begin{array}{l}190 \mathrm{~mm} \\
\text { (Otherwise, } \\
\text { couldn't read the } \\
\text { text) }\end{array}$ \\
\hline 4 & Simulation setup for obtaining the flux at the entrance aperture. & $90 \mathrm{~mm}$ \\
\hline 5 & Direct light simulation at different angles incidence. & $90 \mathrm{~mm}$ \\
\hline 6 & $\begin{array}{l}\text { Flux distribution on the receiver under direct irradiance at angles of } \\
\text { incidence of: (a) } 0^{\circ} \text { along both axes; (b) } 40^{\circ} \text { along the } \mathrm{x} \text {-axis, and (c) } \\
40^{\circ} \text { along the } \mathrm{x} \text {-axis and } 23^{\circ} \text { along the } \mathrm{z} \text {-axis. }\end{array}$ & $90 \mathrm{~mm}$ \\
\hline 7 & Simulation result for the optical concentration gain under direct light. & $90 \mathrm{~mm}$ \\
\hline 8 & $\begin{array}{l}\text { Ray path at large tilt angles, where: (a) at } 30^{\circ} \text { tilt angle, and (b) at } 60^{\circ} \\
\text { tilt angle. }\end{array}$ & $140 \mathrm{~mm}$ \\
\hline 9 & Diffuse light simulation setup. & $90 \mathrm{~mm}$ \\
\hline 10 & Flux distribution on the receiver under diffuse irradiance. & $90 \mathrm{~mm}$ \\
\hline 11 & $\begin{array}{l}\text { Dimensions of the solar cell, where (a) the schematic provided by the } \\
\text { company, and (b) the actual measurement. }\end{array}$ & $90 \mathrm{~mm}$ \\
\hline 12 & $\begin{array}{l}\text { Fabricating the samples: (a) non-concentrating PV cell, and (b) } \\
\text { RADTIRC-PV device. }\end{array}$ & $140 \mathrm{~mm}$ \\
\hline 13 & Experimental setup. & $90 \mathrm{~mm}$ \\
\hline 14 & $\begin{array}{l}\text { The short circuit current and the power generated from the } \\
\text { concentrating and non-concentrating PV devices. }\end{array}$ & $90 \mathrm{~mm}$ \\
\hline 15 & Optical gain of the RADTIRC as a function of the angle of incidence. & $140 \mathrm{~mm}$ \\
\hline 16 & $\begin{array}{l}\text { Errors introduced in the device, showing: (a) misalignment between } \\
\text { the exit aperture and the solar PV cell that occurred during the } \\
\text { assembly process, and (b) small particles introduced in the } \\
\text { RADTIRC during the manufacturing process. }\end{array}$ & $90 \mathrm{~mm}$ \\
\hline 17 & Experimental setup for outdoor diffuse light experiments. & $90 \mathrm{~mm}$ \\
\hline 18 & $\begin{array}{l}\text { Location surrounding for outdoor diffuse light experiment: (a) back } \\
\text { side; (b) right side, and (c) left side. }\end{array}$ & $90 \mathrm{~mm}$ \\
\hline
\end{tabular}

\begin{tabular}{|c|l|l|}
\hline Table & Description & $\begin{array}{l}\text { Proposed size } \\
\text { (width) }\end{array}$ \\
\hline 1 & Main characteristics of the components used in indoor experiments. & $190 \mathrm{~mm}$ \\
\hline
\end{tabular}




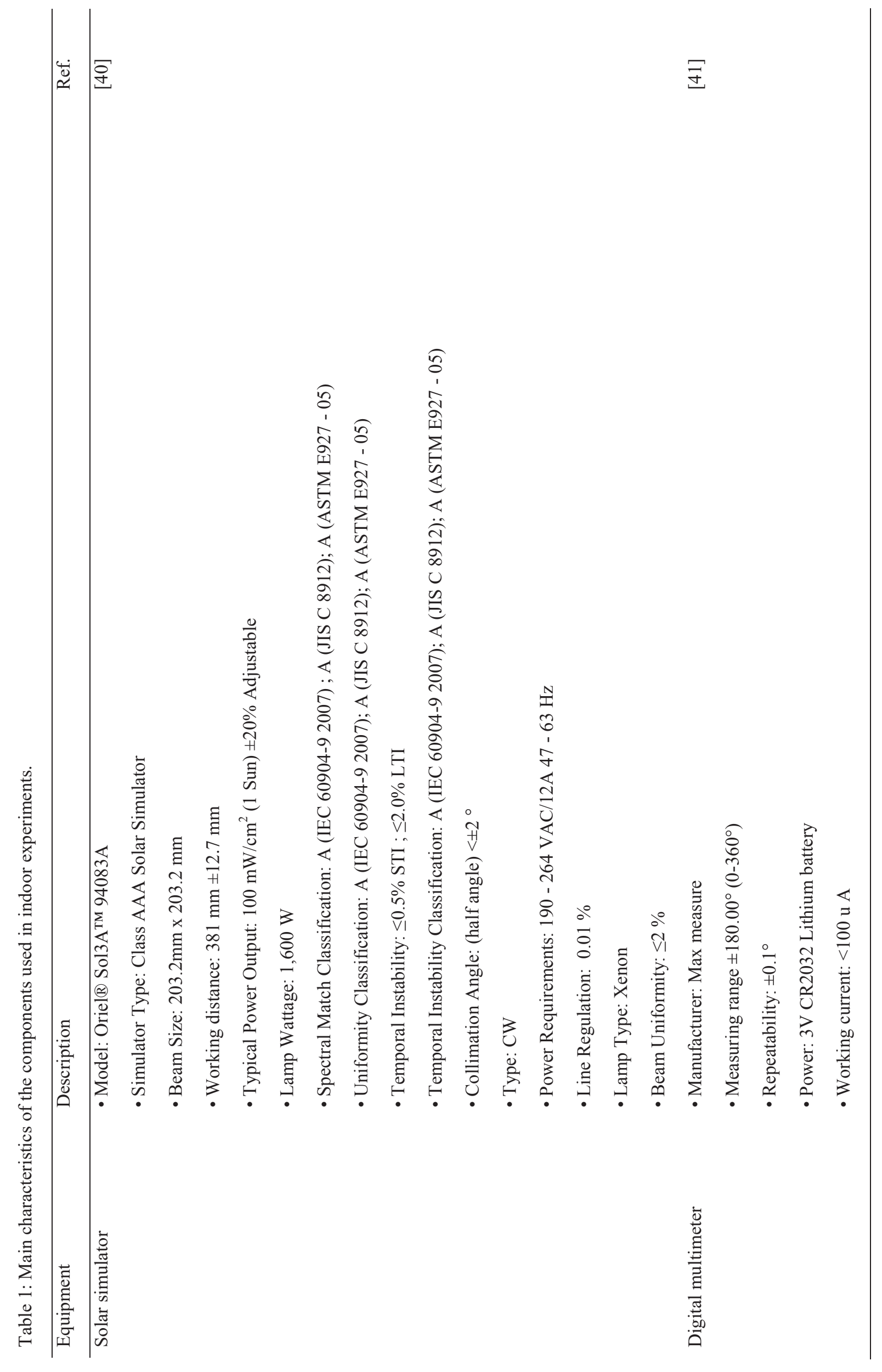




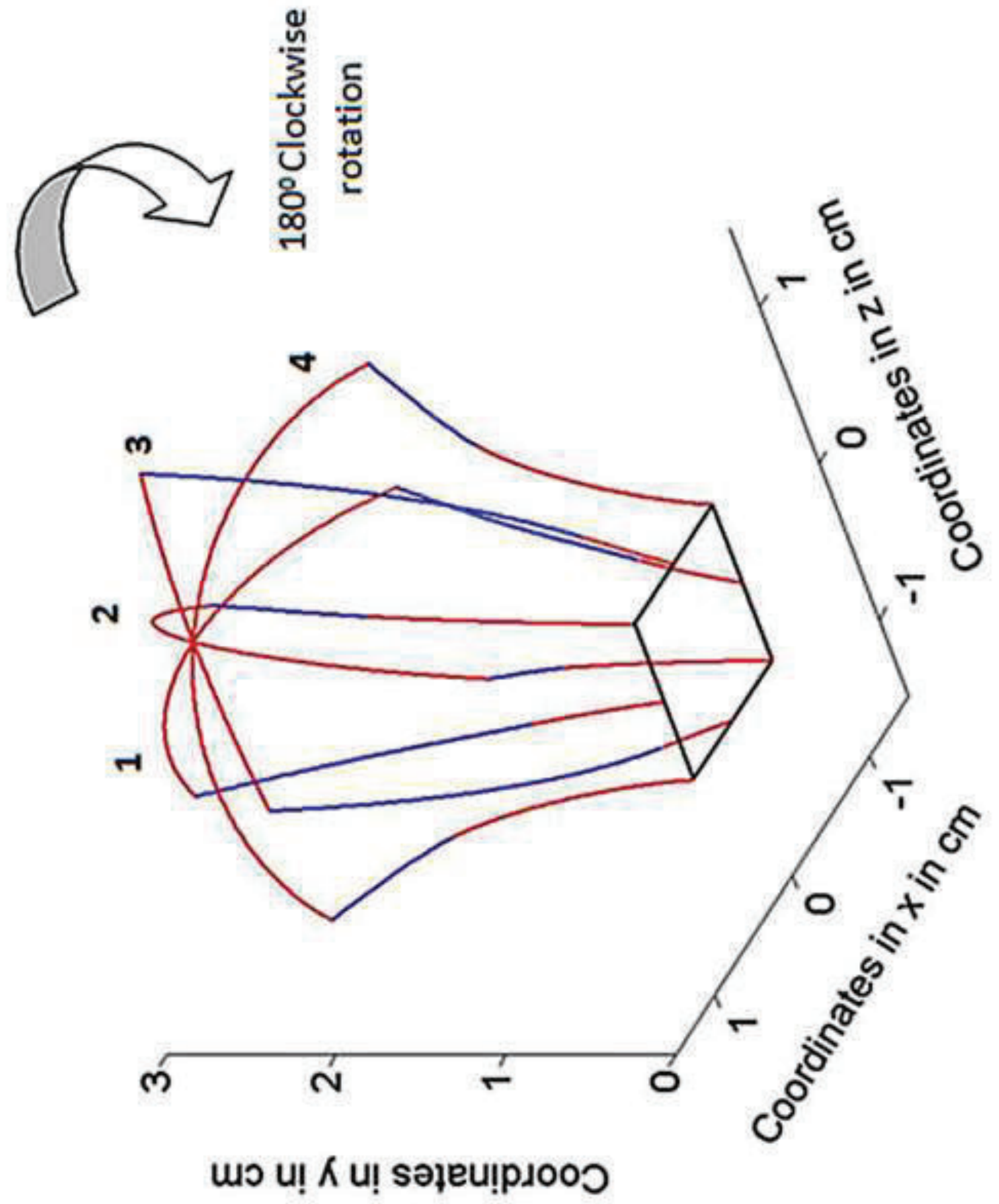



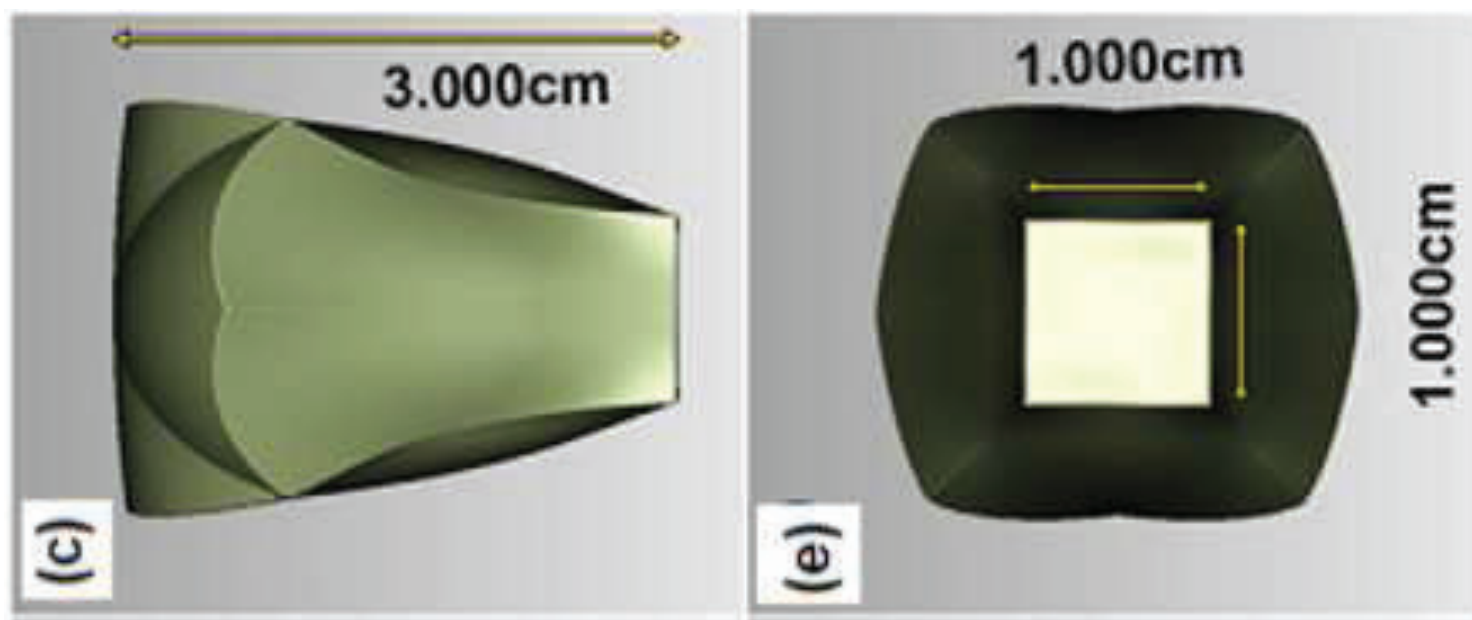

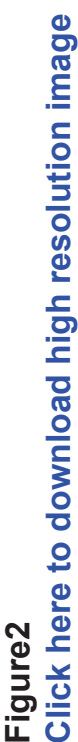
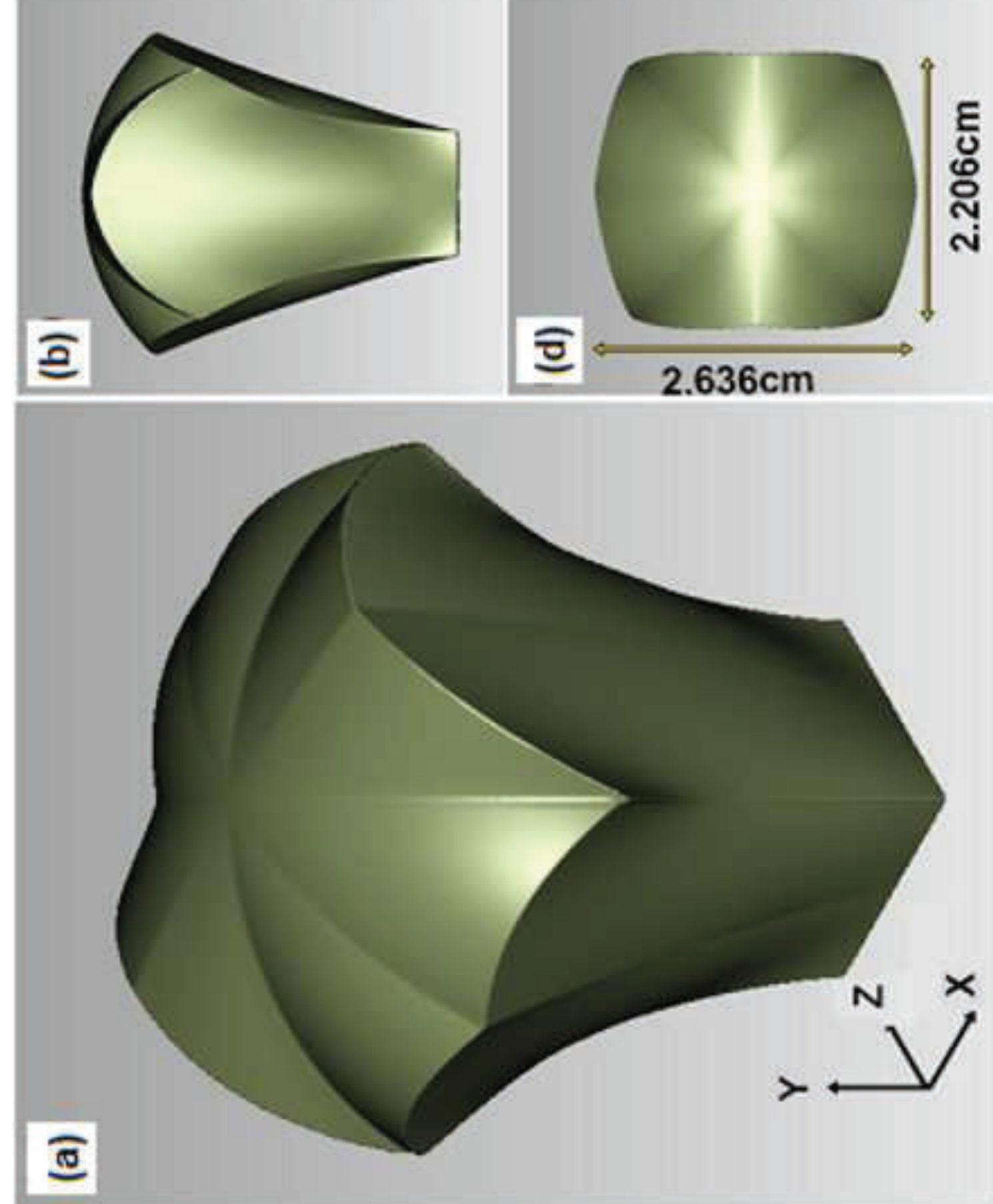


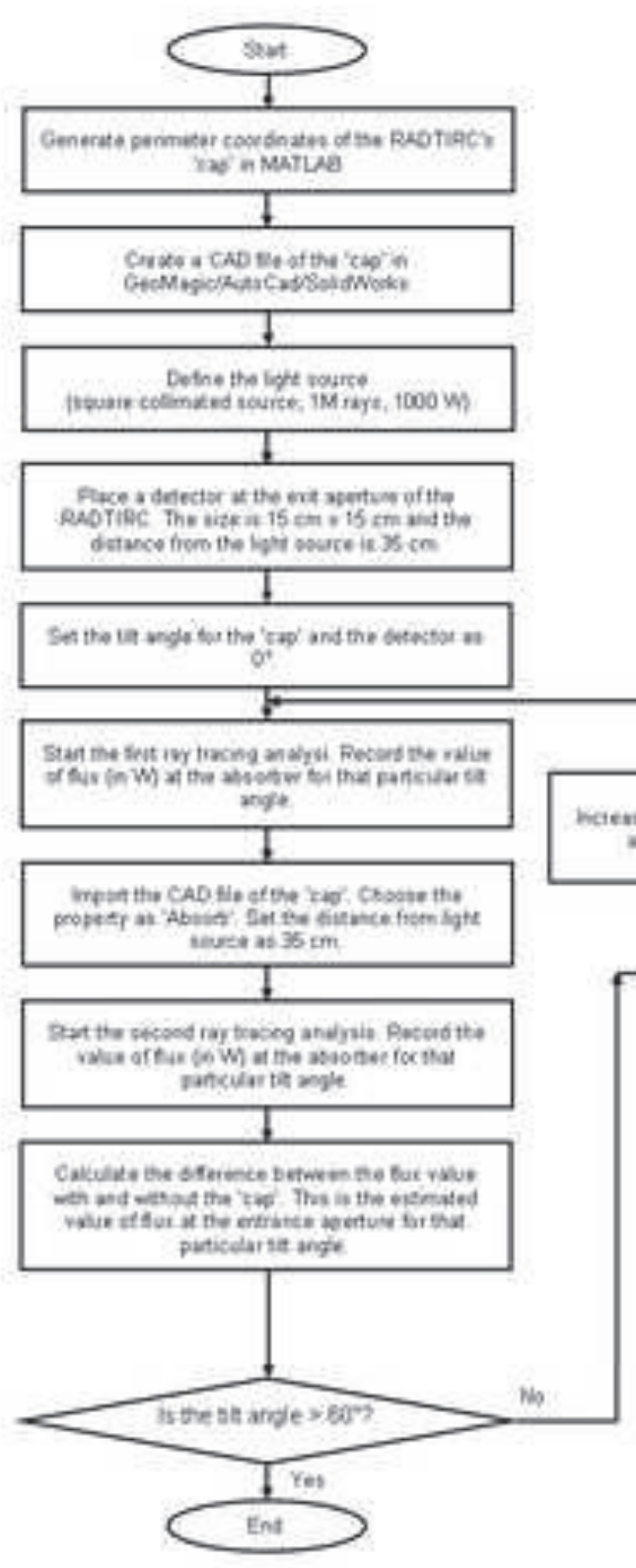

(a)

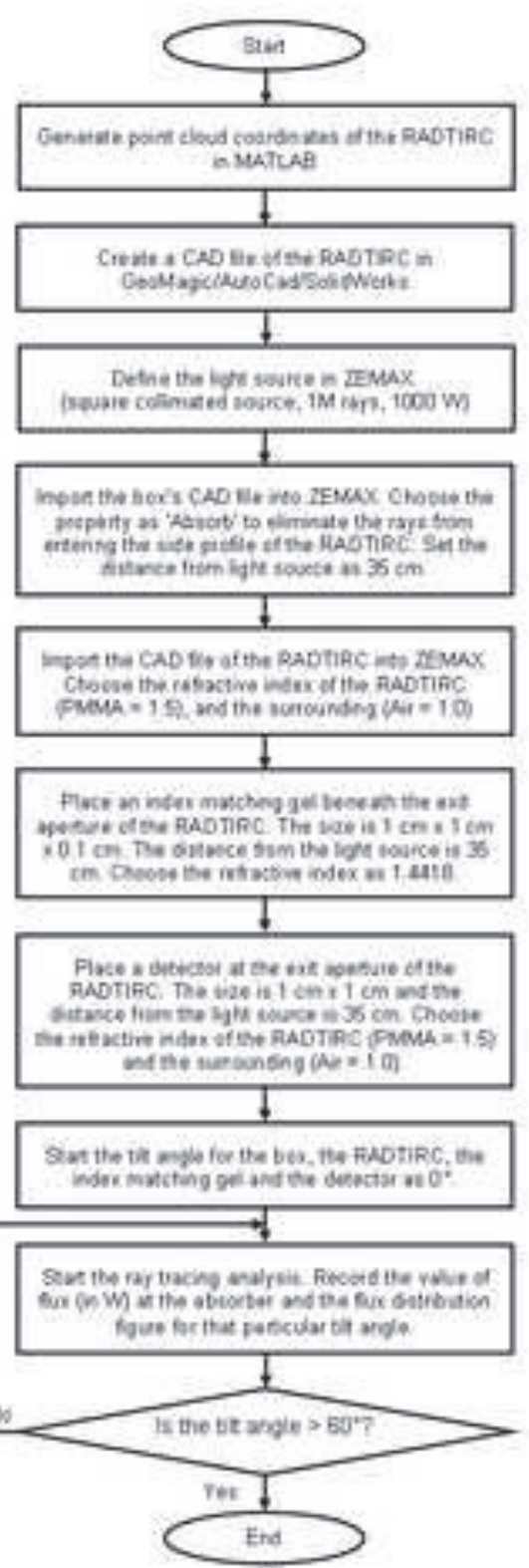

(b) 


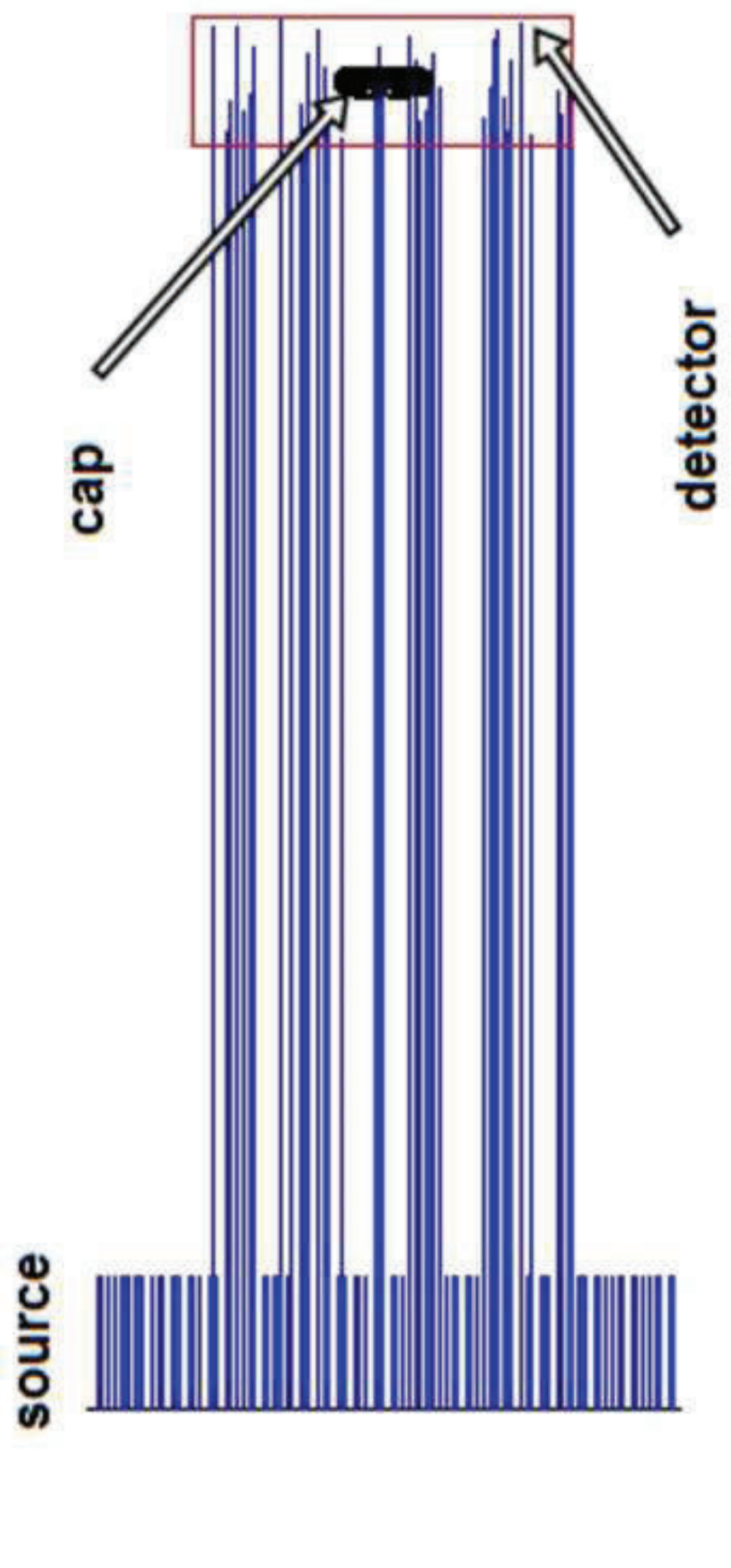




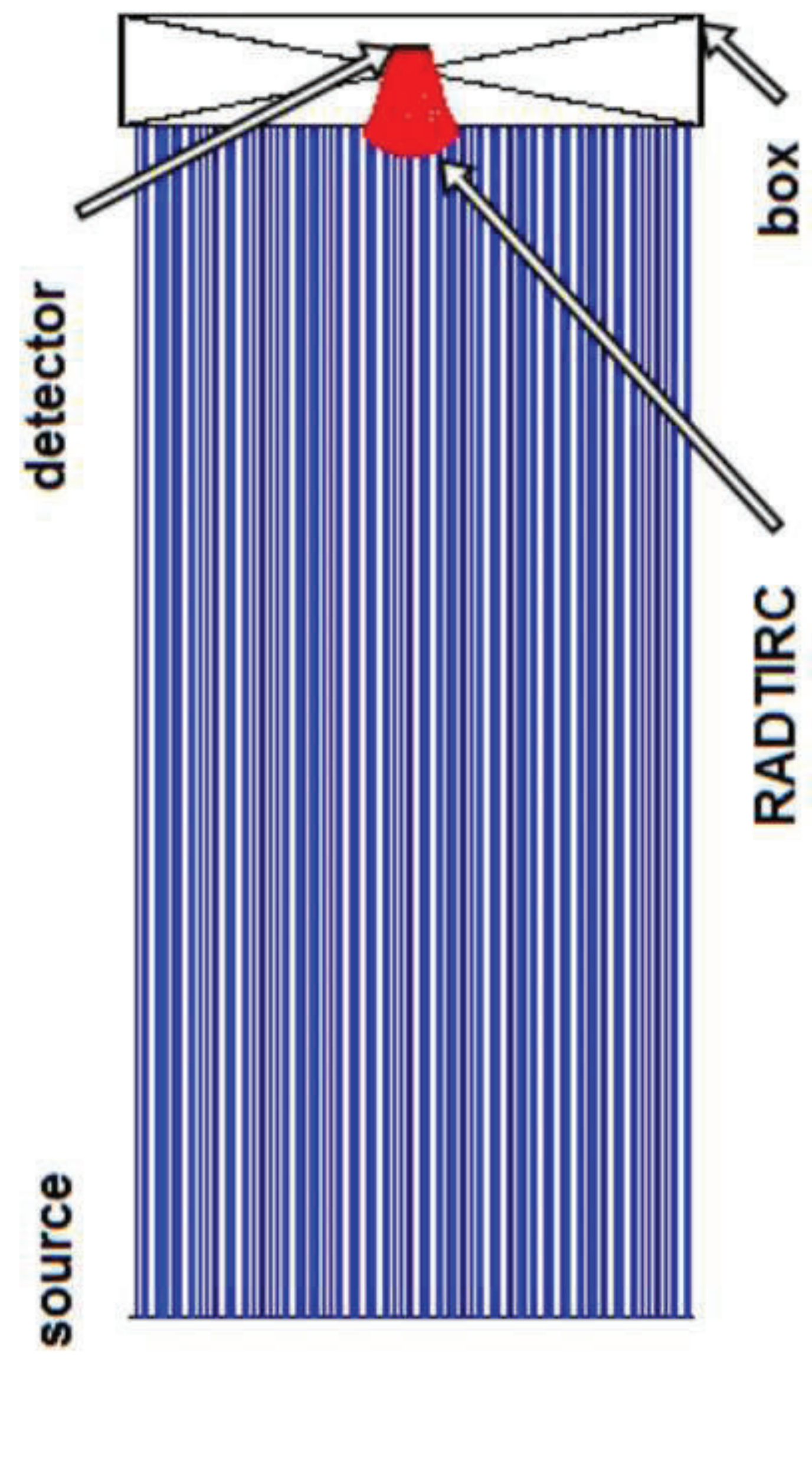



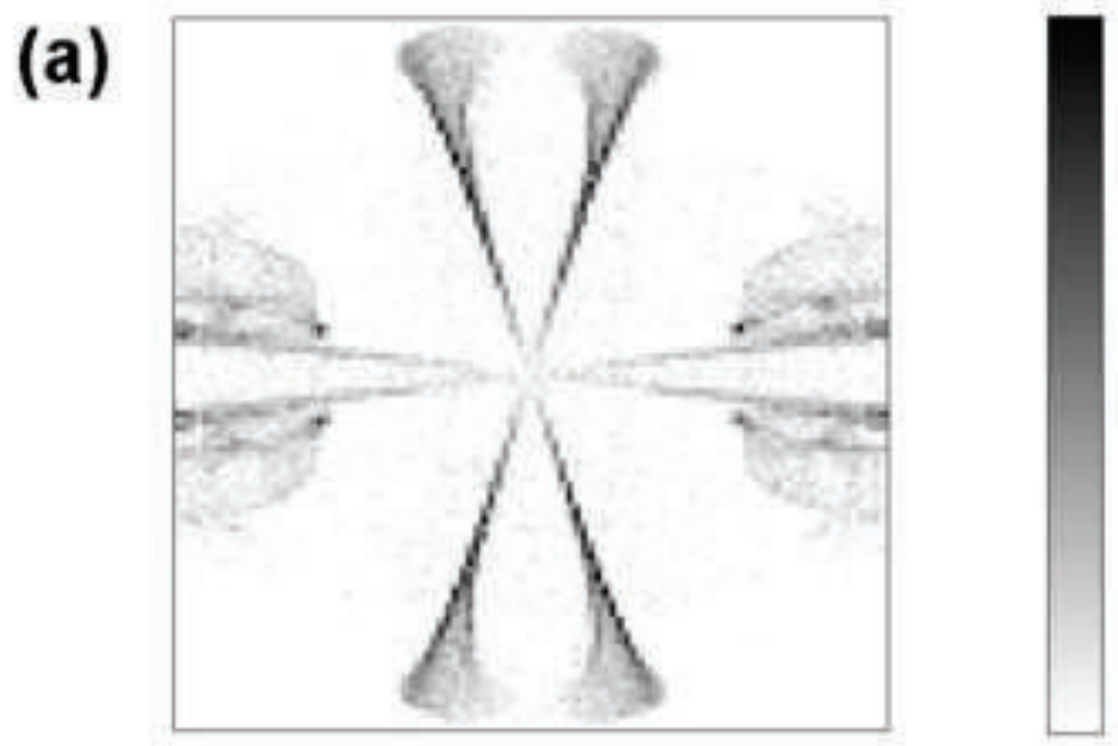

380.0000

342,0000

304.0000

266.0000

229.0000

190.0000

152.0000

114,0000

76.0000

38.0000

0.0000

(b)
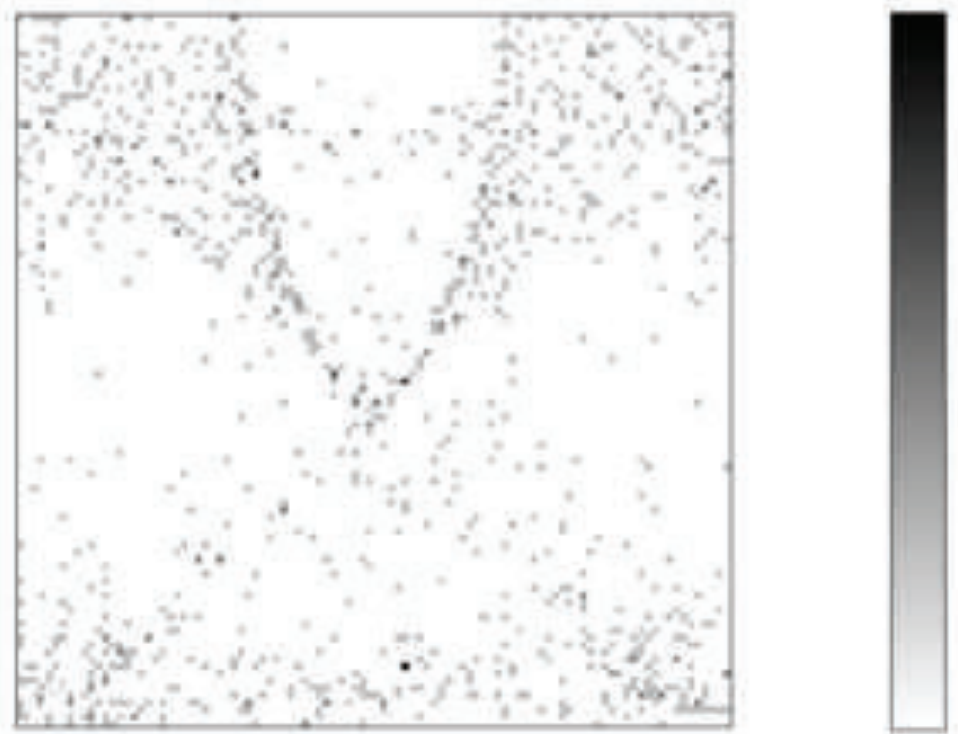

40.0000

36.0000

32.0000

28.0000

24,0000

20.0009

16.0000

12.0000

B. 0000

4,0000

0.0000

(c)
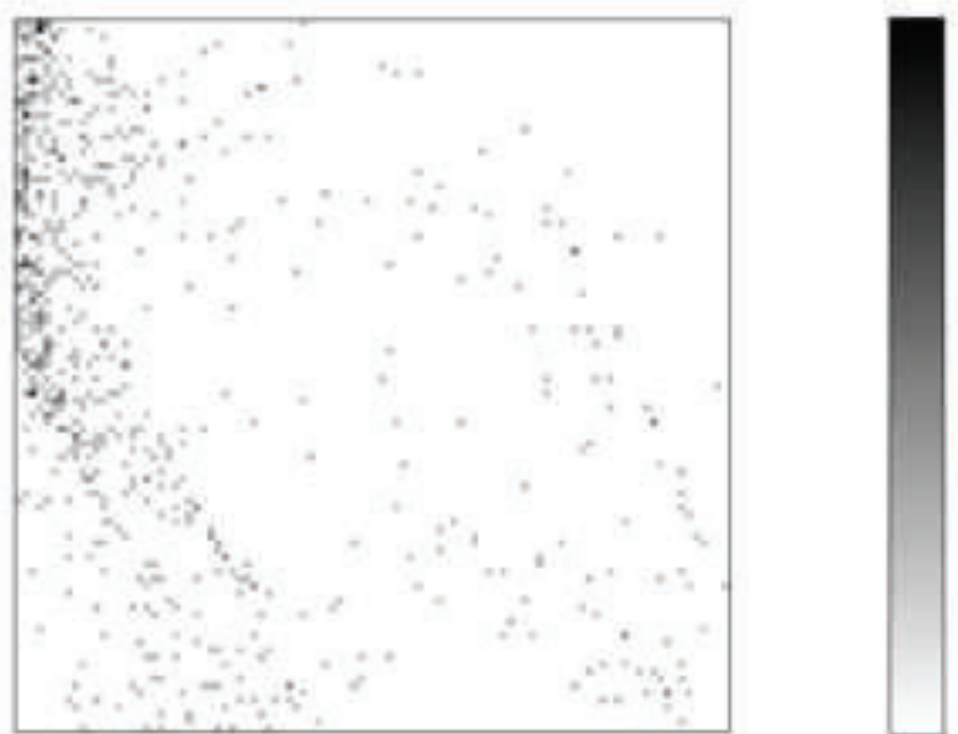

40.0000

36.0000

32.0000

28.0000

24.0000

20.0000

16.0000

12.0000

7. 0000

4. 0000

0.0000 


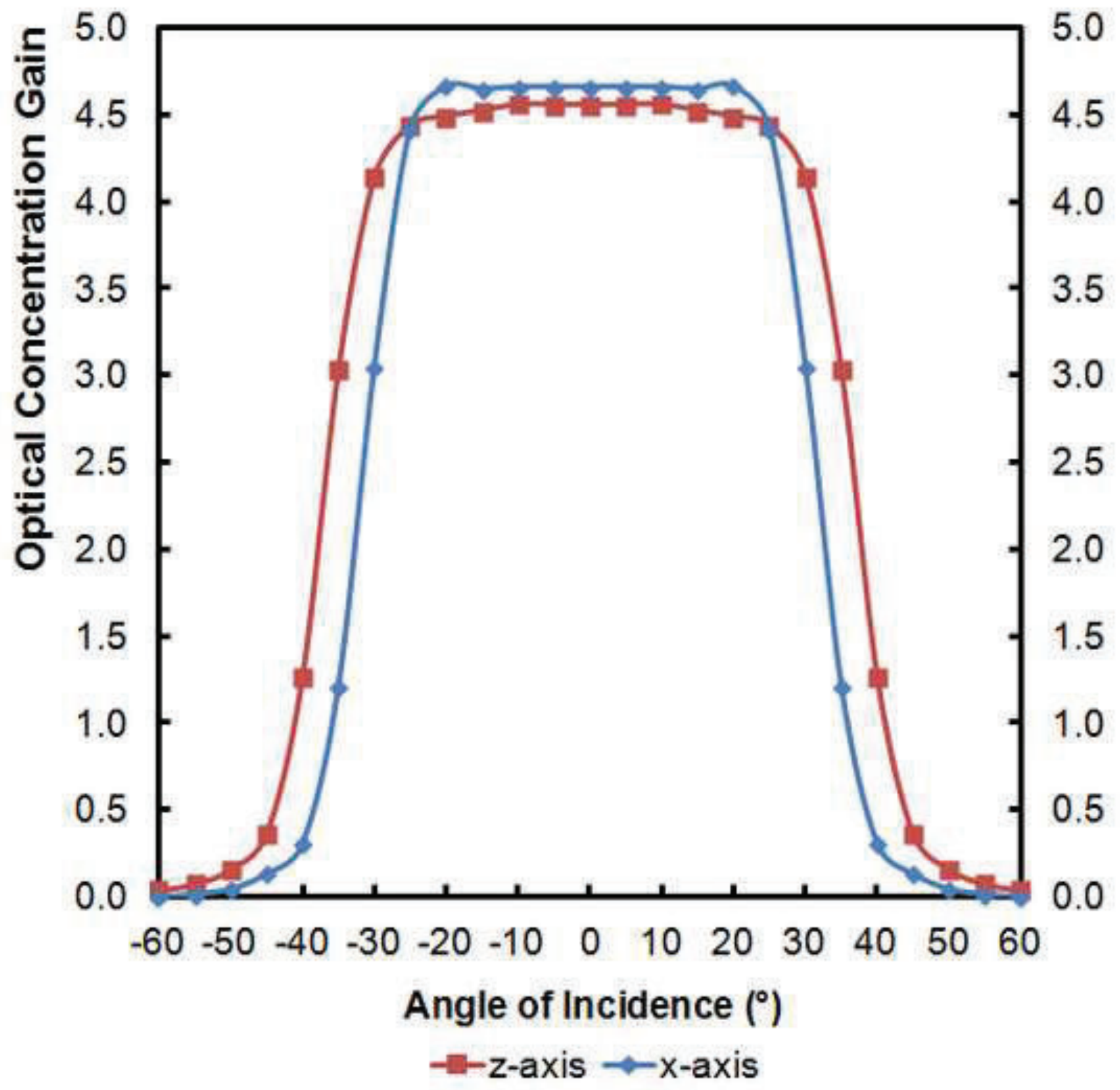




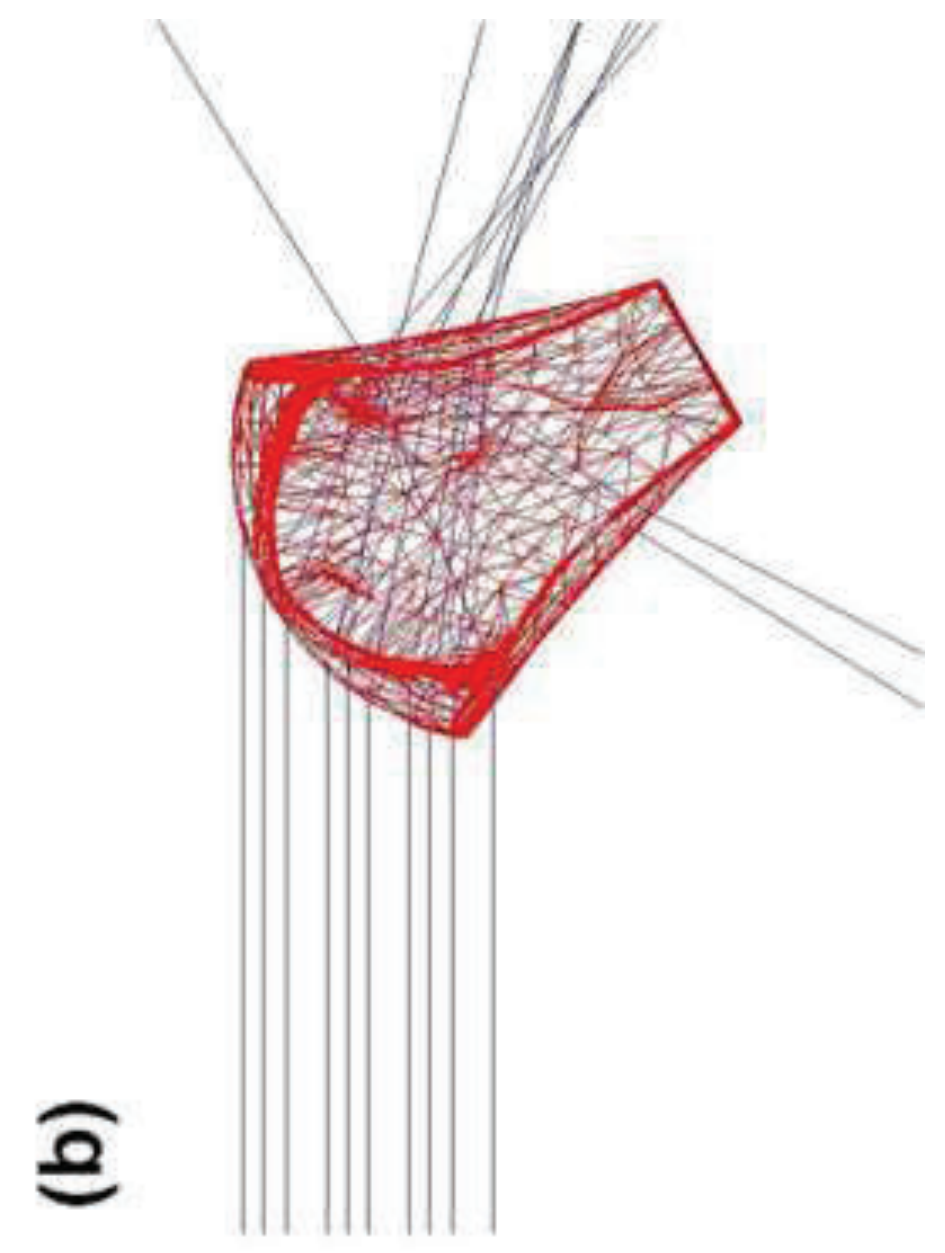

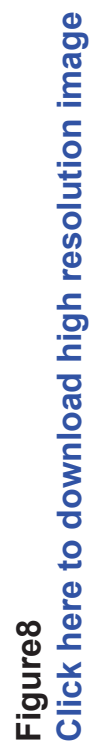

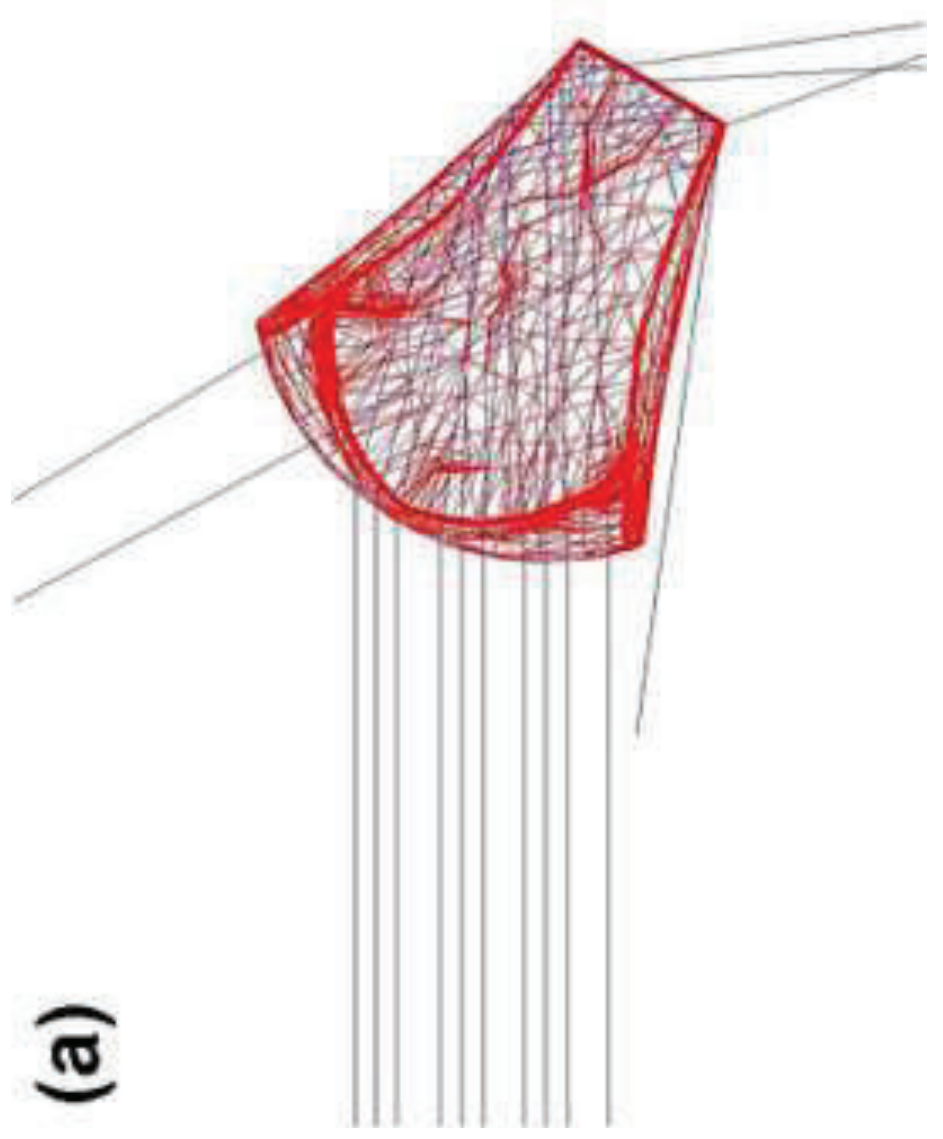




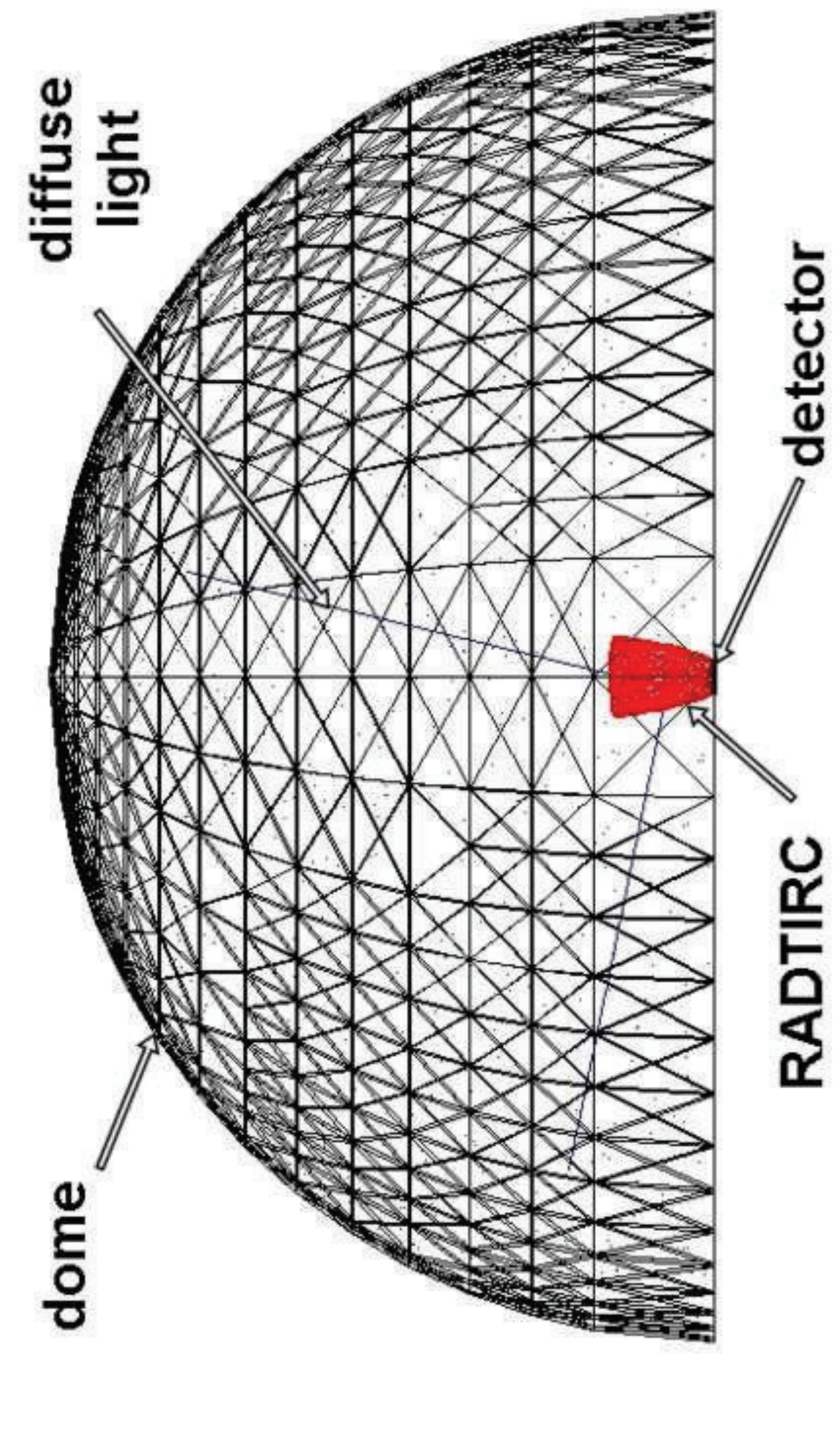




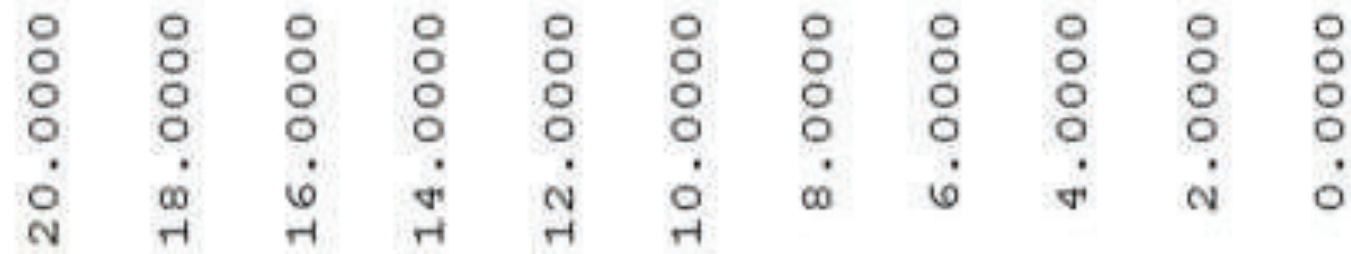

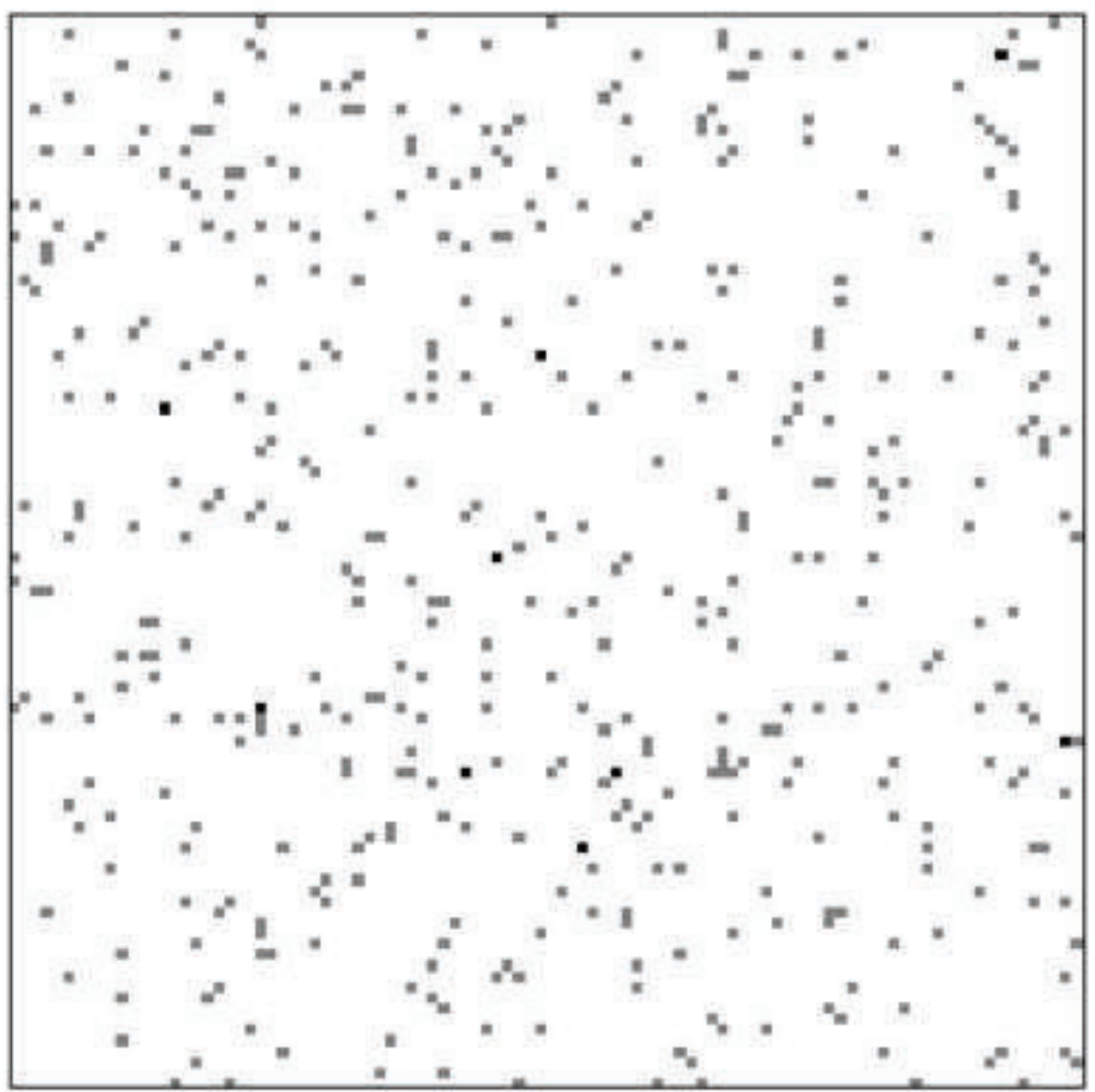

응 


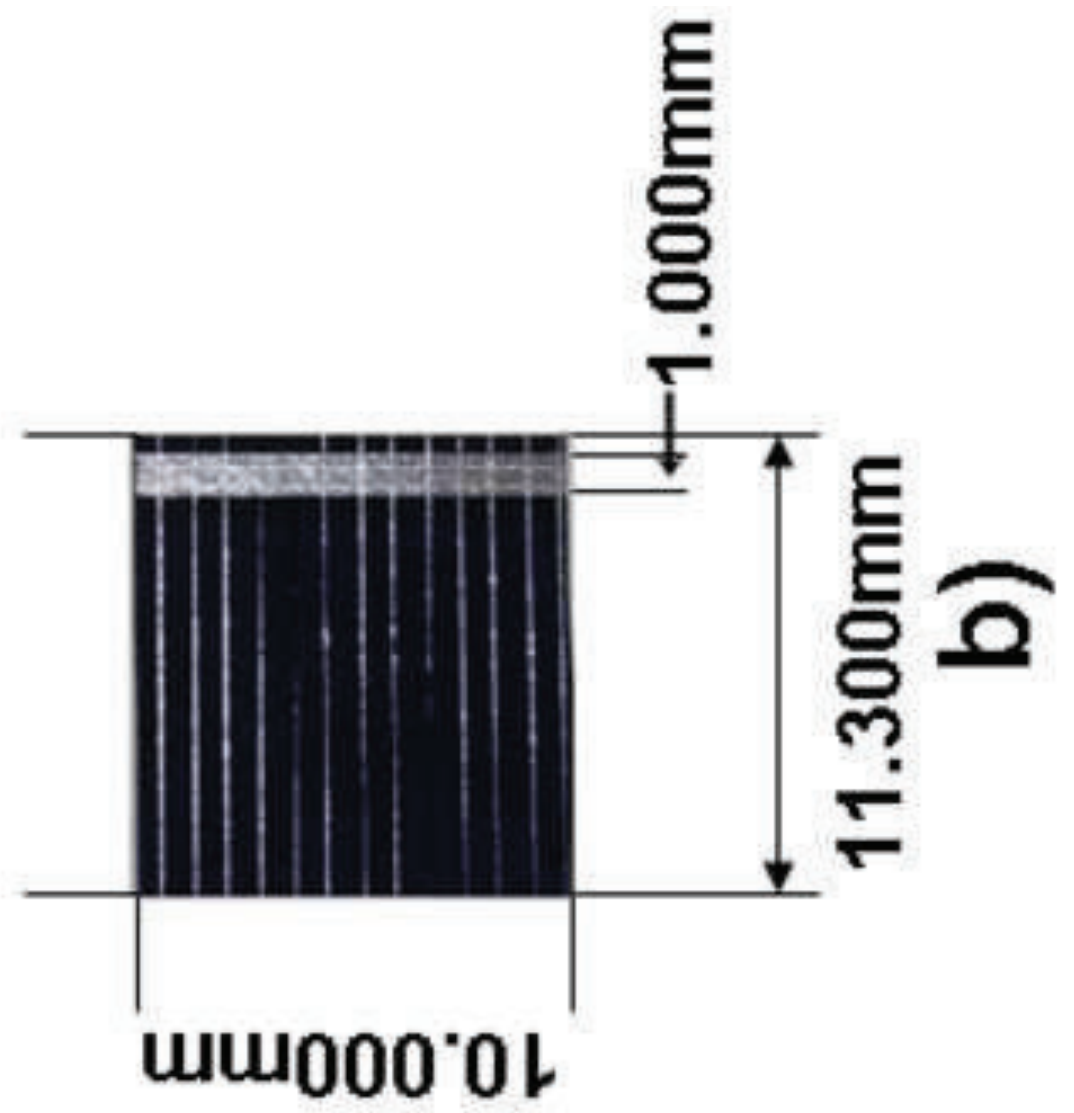

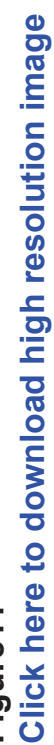

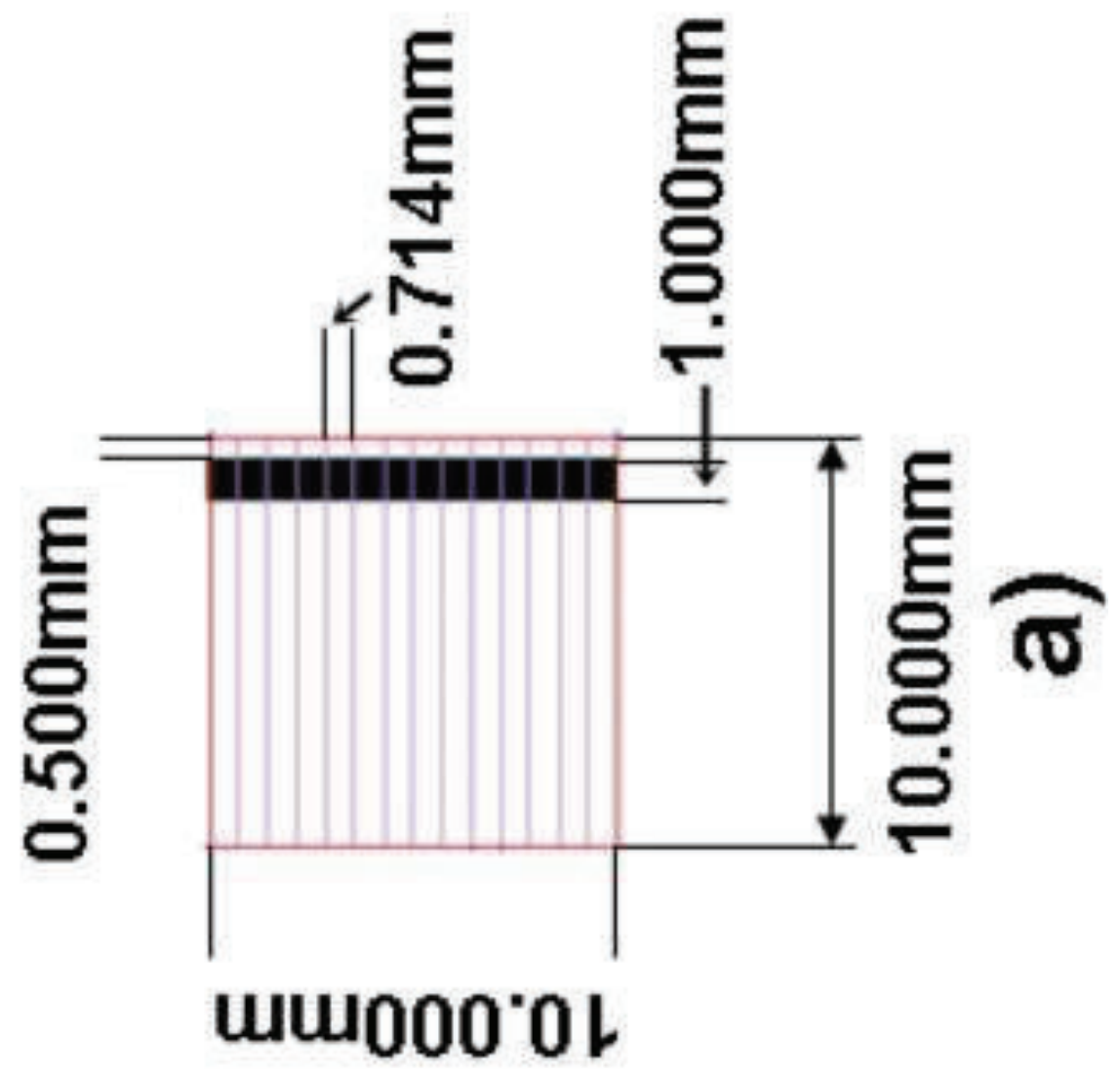




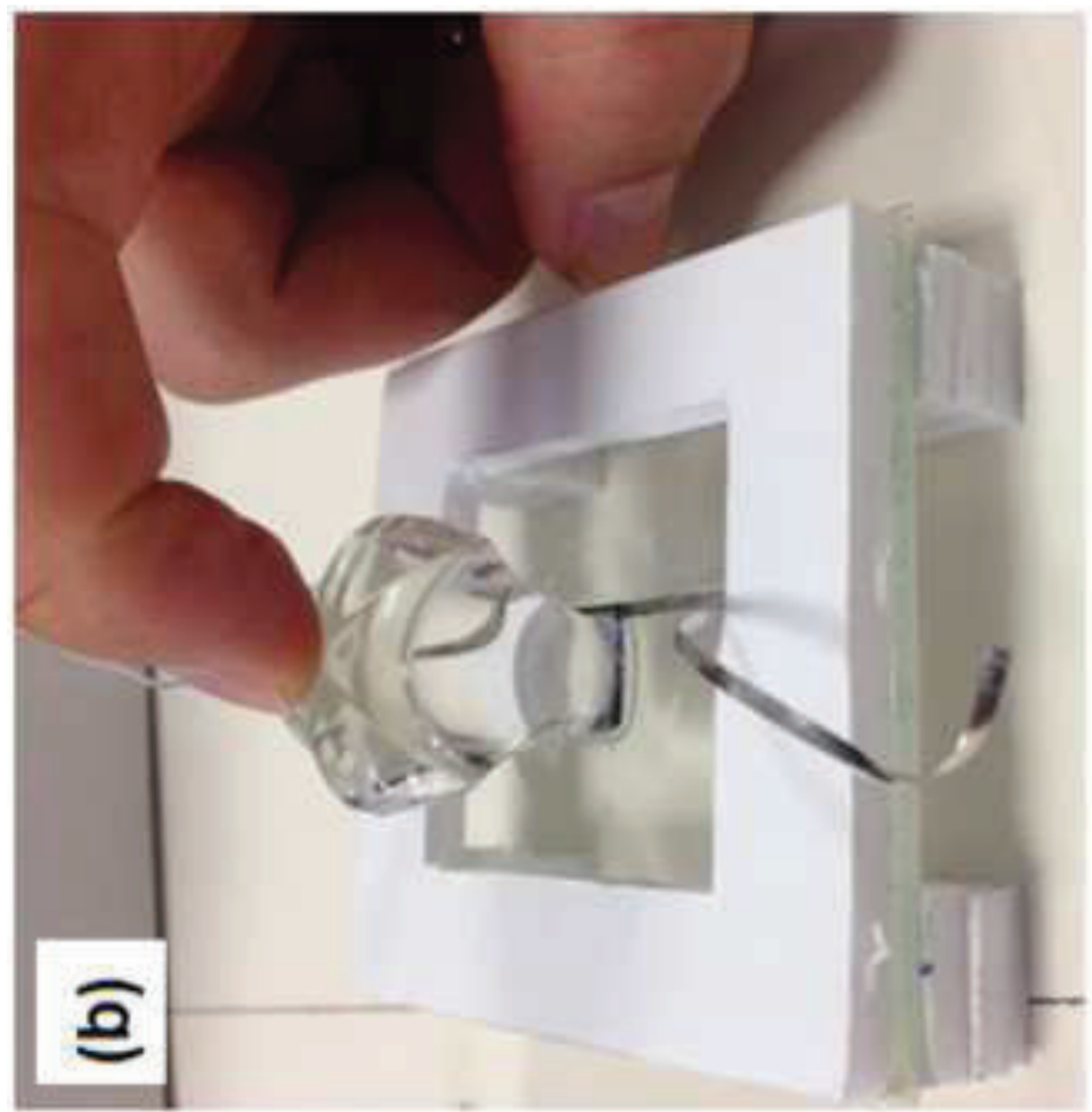

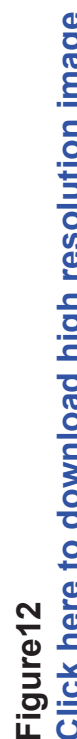

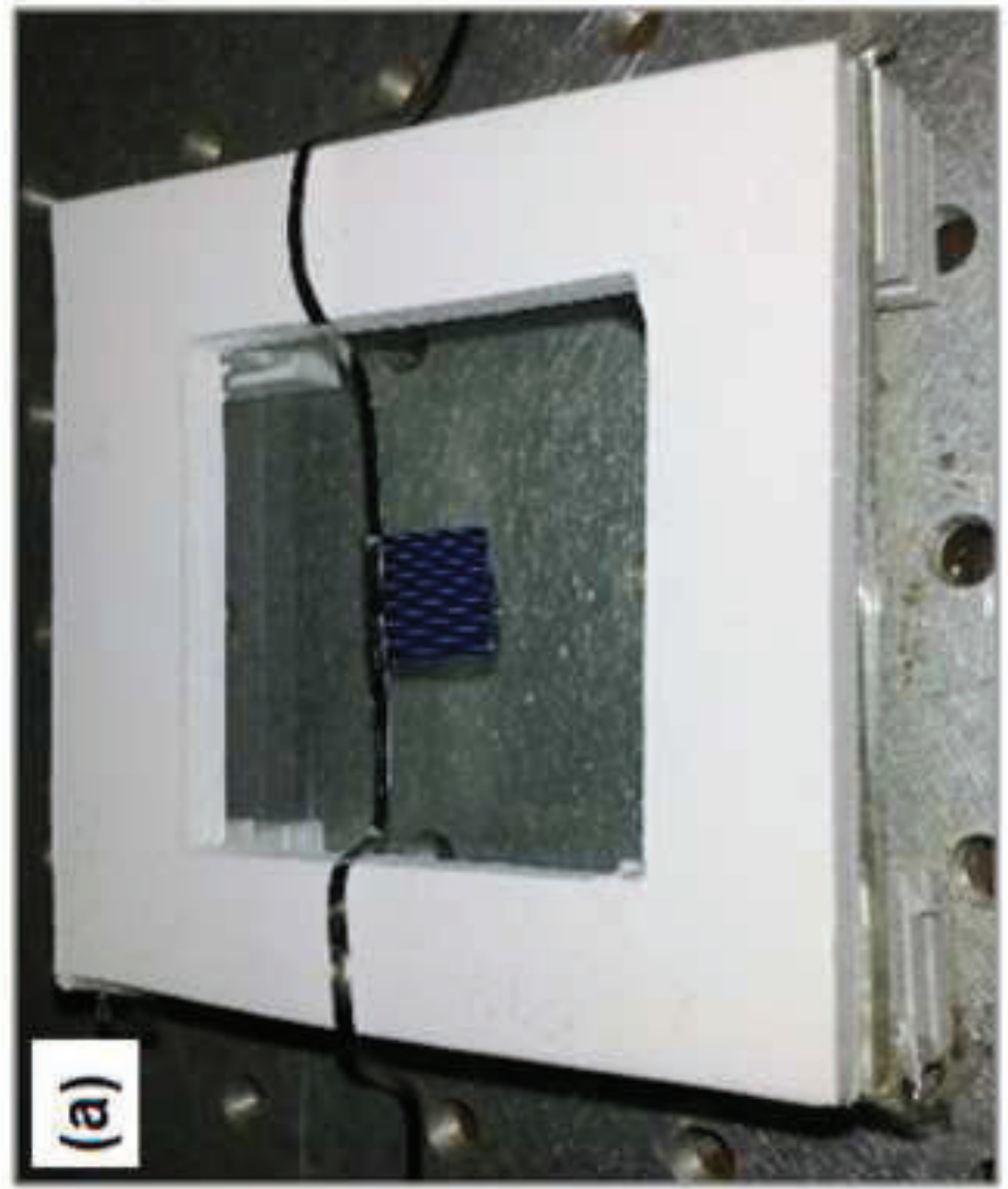




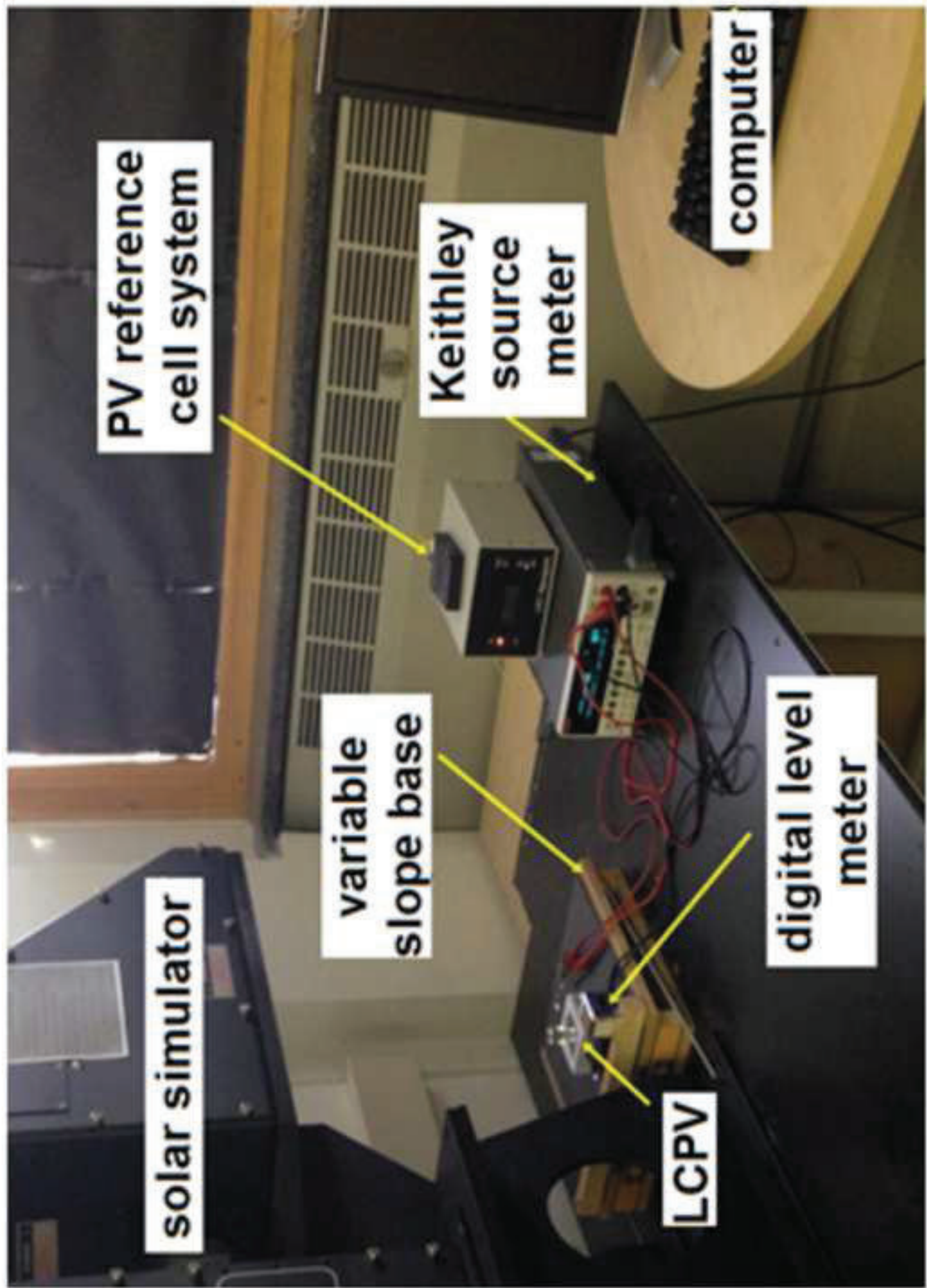

m

3

证 
(MU) / d 'ләмо d

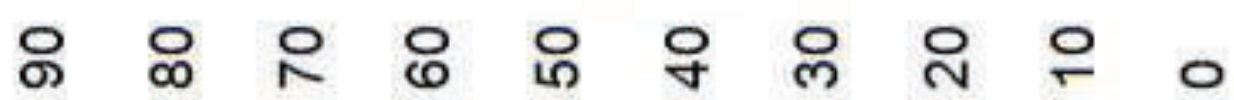

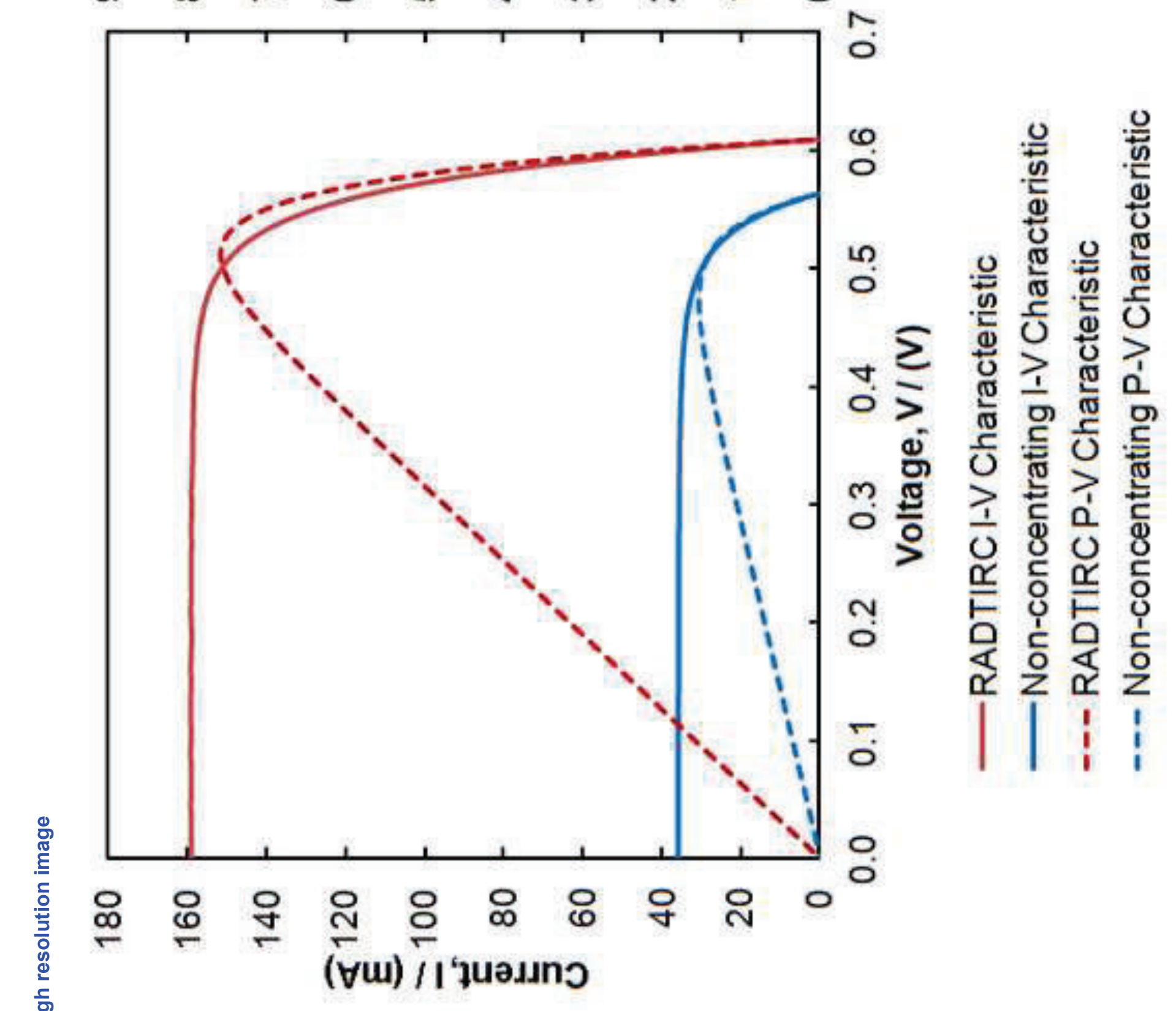



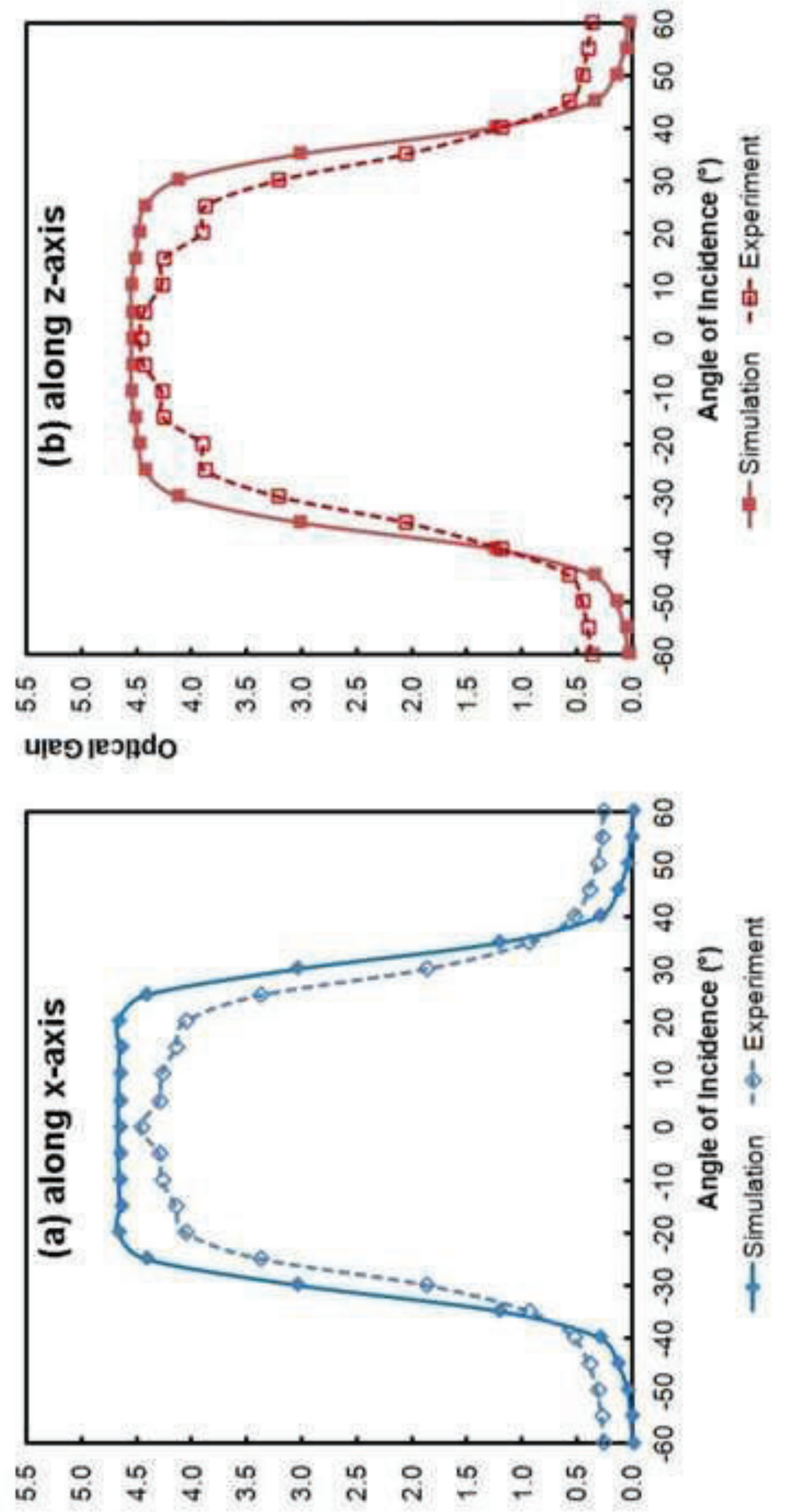
upeэreэndo 


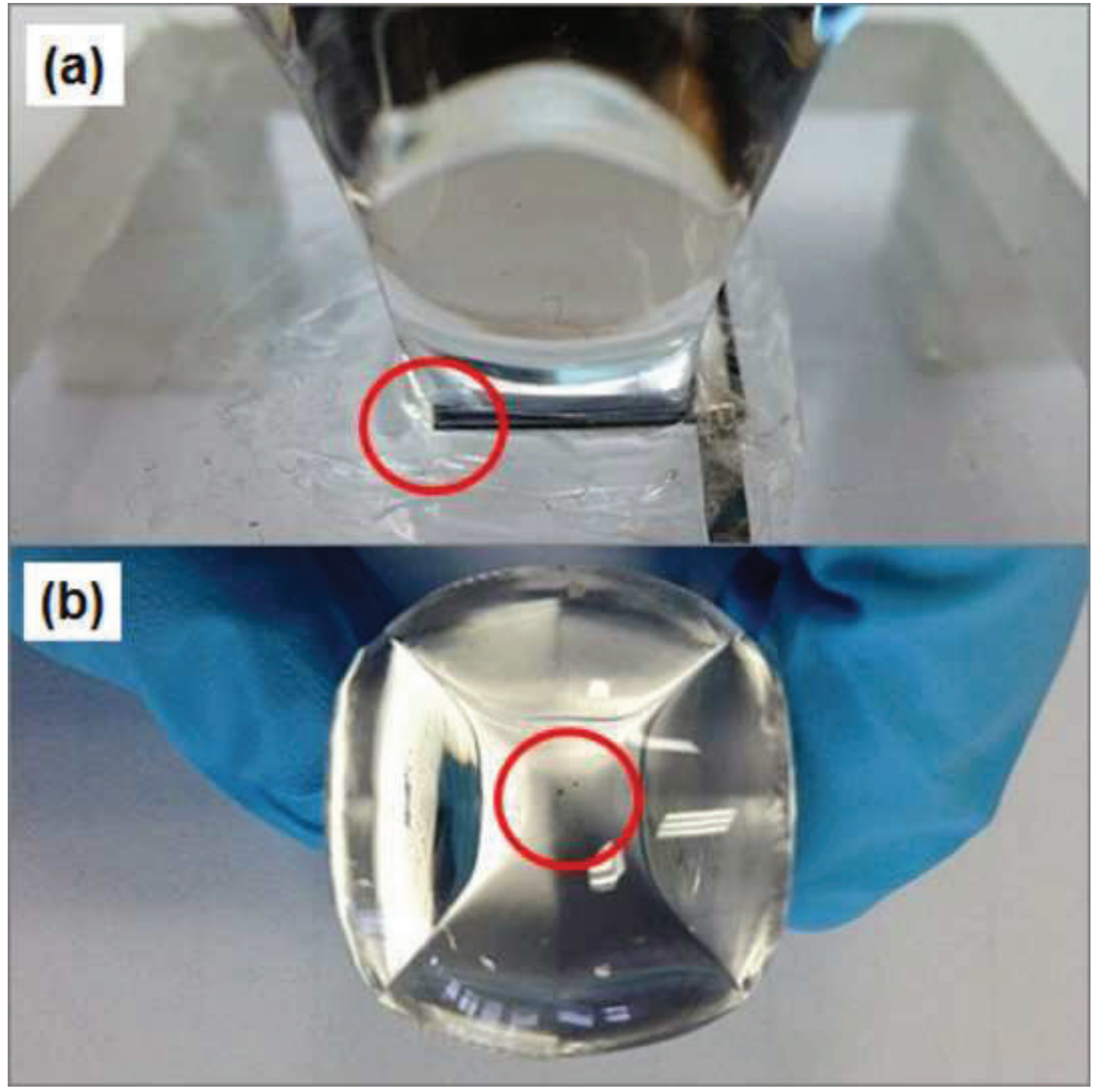




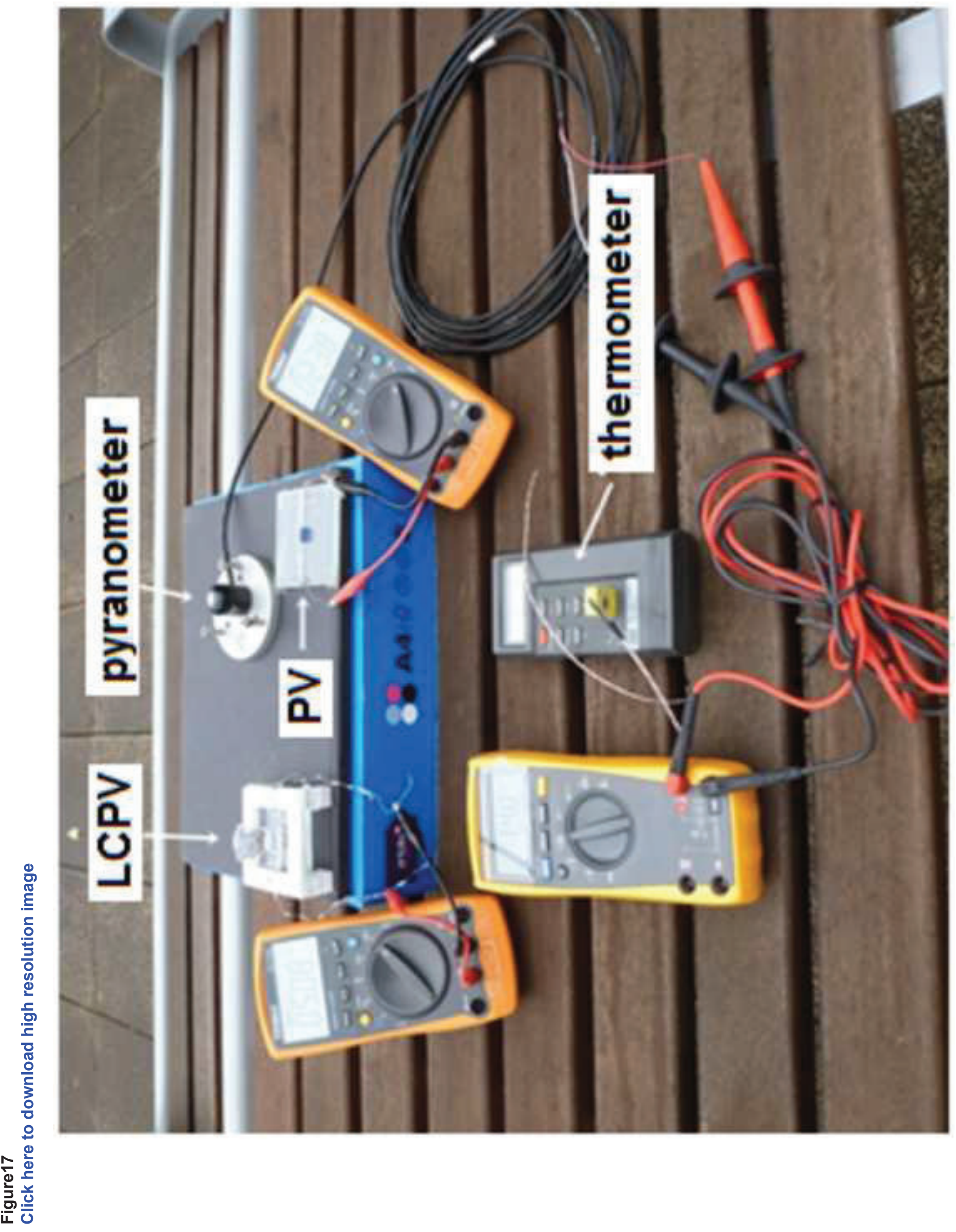




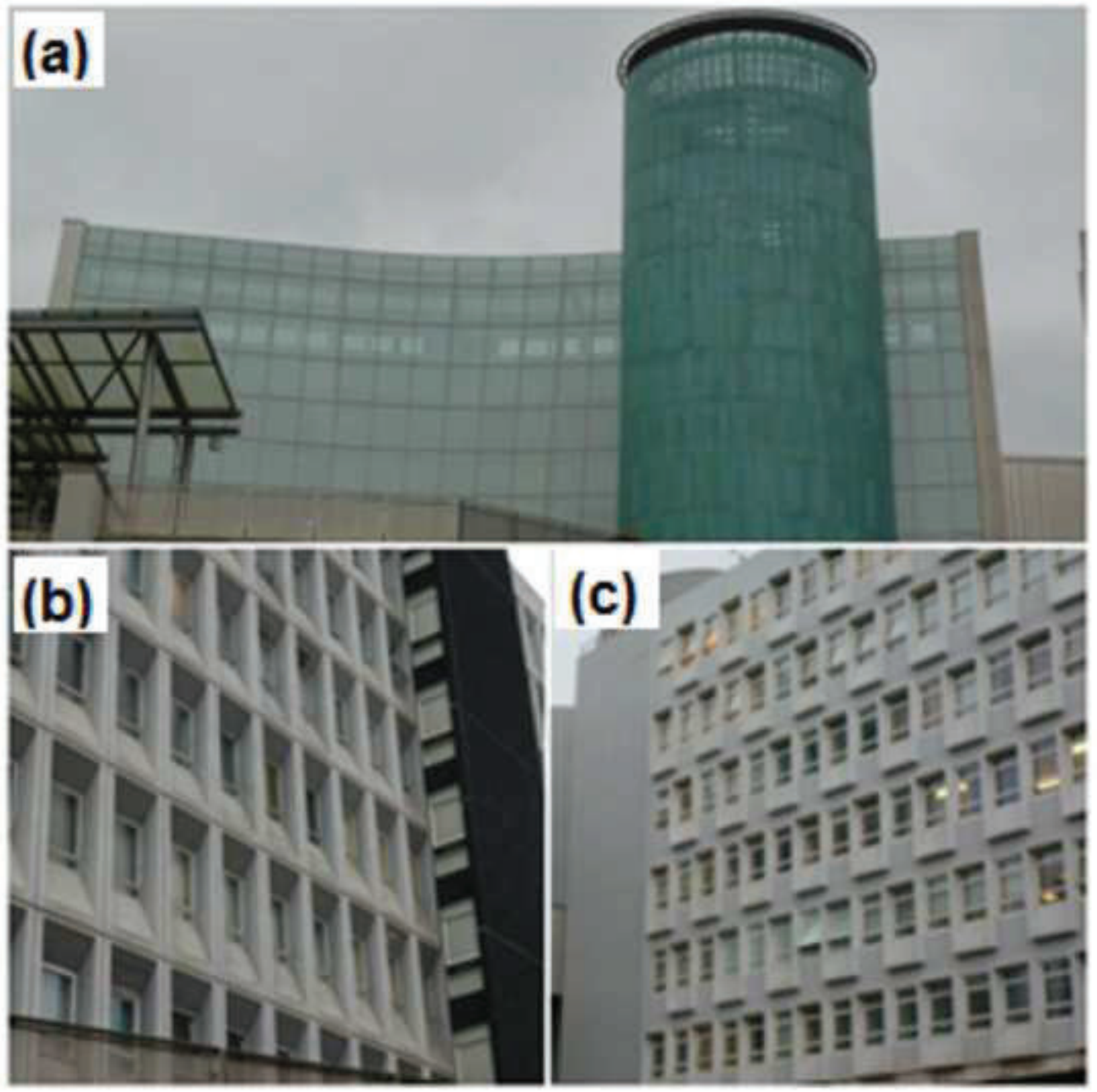

